\title{
CONSTITUINTES QUÍMICOS DE Solanum buddleifolium Sendtn
}

Francisco das Chagas L. Pinto, Maria da Conceição M. Torres, Edilberto R. Silveira e Otília Deusdênia L. Pessoa*

Departamento de Química Orgânica e Inorgânica, Centro de Ciências, Universidade Federal do Ceará, CP 12.200, 60021-940

Fortaleza - CE, Brasil

Raimundo Braz-Filho

Departamento de Química, Universidade Estadual do Norte Fluminense, 28013-602 Campos - RJ, Brasil

Maria Lenise da Silva Guedes

Departamento de Botânica, Instituto de Biologia, Universidade Federal da Bahia, 40170-115, Campus Universitário de Ondina - BA, Brasil

Recebido em 6/5/13; aceito em 20/5/13; publicado na web em 1/7/13

\begin{abstract}
CHEMICAL CONSTITUENTS OF Solanum buddleifolium Sendtn. The chemical investigation of the stem EtOH extract of $S$. buddleifolium resulted in the isolation of terpenoids, amides, lignans and a steroidal alkaloid. Based on HRMS, IR and ${ }^{1} \mathrm{H}$ and ${ }^{13} \mathrm{C}$ NMR data analysis, the structures of the isolated compounds were identified as: 13-hydroxysolavetivone, betulinic acid, $\mathrm{N}$-trans-caffeoyltyramine, $\mathrm{N}$-trans-feruloyldopamine, $\mathrm{N}$-trans-p-cumaroyltyramine, $\mathrm{N}$-trans-feruloyltyramine, $\mathrm{N}$-trans-feruloyl3'-O-methoxydopamine, alangilignoside $\mathrm{C}$, isolariciresinol, polistachiol, (+)-( $\left.8 R, 7^{\prime} S, 8^{\prime} S\right)$-3 $\alpha$-O-( $\beta$-D-glucopiranosyl)-lioniresinol, (-)-( $\left.8 S, 7^{\prime} R, 8^{\prime} R\right)-3 \alpha-\mathrm{O}-(\beta-\mathrm{D}$-glucopiranosyl)-lioniresinol and solamargine. The occurrence of terpenoids and amides is common in Solanum, unlike lignans which are rare. The isolated lignans described in this work are reported for the first time in the genus Solanum.
\end{abstract}

Keywords: Solanum buddleifolium; amides; lignans.

\section{INTRODUÇÃO}

O Brasil abriga em seus vários ecossistemas grande diversidade de plantas, constituindo-se uma das mais ricas floras do mundo e, portanto, um arsenal de matéria-prima para a produção de fitofármacos e fitoterápicos. O nordeste Brasileiro, uma região onde predomina a caatinga, é particularmente rico em plantas usadas na medicina popular como preventivo ou no tratamento de doenças. ${ }^{1,2}$

A família Solanaceae, reconhecida por sua importância econômica, envolve vários gêneros de importância medicinal. ${ }^{3}$ Neste contexto temos investigado incessantemente plantas dos gêneros Acnistus e Solanum, com vistas ao isolamento de seus metabolitos secundários. ${ }^{4-6}$ Plantas do gênero Solanum são facilmente encontradas no Nordeste do Brasil onde, em geral, recebem a designação popular de jurubebas, muitas das quais são indicadas para o tratamento de doenças da pele e/ou desordens hepáticas e digestivas. ${ }^{5,7}$ Como exemplo tem-se $S$. paniculatum um fitoterápico reconhecido pela Farmacopeia Brasileira. ${ }^{8}$ Em trabalhos prévios, foram isolados a partir de $S$. asperum, glicoalcaloides com propriedades antifúngicas, ${ }^{5}$ enquanto de $S$. campaniforme foram obtidos alcaloides solanidanos com potente efeito antiofídico sobre o veneno de Bothrops pauloensis (Jararaca-pintada). ${ }^{4}$ Dando continuidade ao estudo envolvendo plantas deste gênero, neste trabalho são relatados os constituintes químicos de $S$. buddleifolium, o qual está sendo investigado pela primeira vez.

\section{RESULTADOS E DISCUSSÃO}

O estudo químico do extrato etanólico de talos de $S$. buddleifolium permitiu o isolamento e a identificação de terpenoides, amidas e lignanas (Figura 1), cujas estruturas foram determinadas com base em dados espectrais de $\mathrm{RMN}{ }^{1} \mathrm{H} \mathrm{e}{ }^{13} \mathrm{C}$, incluindo experimentos bidimensionais (COSY, HSQC e HMBC), além de IV e EMAR-IES,

*e-mail: opessoa@ufc.br e finalmente confirmação por comparação com dados disponíveis na literatura.

Da fração em diclorometano, proveniente do fracionamento líquido-líquido do extrato $\mathrm{EtOH}$, foi isolada e identificada a mistura binária dos esteróides $\beta$-sitosterol e estigmasterol, bem como a mistura de suas respectivas formas glicosiladas; ${ }^{9} \mathrm{o}$ triterpeno ácido betulínico (1, P.F. $210-212{ }^{\circ} \mathrm{C}$, lit. P.F. $\left.210-215{ }^{\circ} \mathrm{C}\right),{ }^{10} \mathrm{e}$ o sesquiterpeno 13-hidroxisolavetivona (2). ${ }^{11}$ Também foram isoladas as amidas: $N$-trans-cafeoiltiramina (7), ${ }^{12} \mathrm{~N}$-trans-feruloildopamina (8), ${ }^{13}$ $\mathrm{N}$-trans-p-cumaroiltiramina (6), ${ }^{13,14} \mathrm{~N}$-trans-feruloiltiramina (3), ${ }^{14,15}$ e $N$-trans-feruloil-3'-O-metoxidopamina (4), ${ }^{16}$ cujos dados de RMN ${ }^{13} \mathrm{C}$ encontram-se dispostos na Tabela 1.

Os espectros de $\mathrm{RMN}{ }^{1} \mathrm{H}$ de todas as amidas $(\mathbf{3}, \mathbf{4 , 6 - 8})$ exibiram sinais para dois anéis aromáticos (sistemas tipo AMX e/ou AA'BB'), mostraram dupletos na faixa de $\delta 7,45$ a 6,34 e constante de acoplamento $(J)$ próximo de $15,5 \mathrm{~Hz}$, compatíveis com hidrogênios de sistemas $\alpha, \beta$-conjugados, envolvendo dupla ligação com configuração trans. Em adição, exibiram também dois tripletos na faixa de $\delta 3,44$ a 2,74 com valor de $J$ de cerca de $7,3 \mathrm{~Hz}$ indicando um sistema de spins para dois grupos metilenos, um dos quais ligados a nitrogênio (- $\mathrm{NHCH}_{2} \mathrm{CH}_{2}-$ ) (ver material suplementar). Os espectros de $\mathrm{RMN}{ }^{13} \mathrm{C}$ dos compostos acima mencionados mostraram claramente sinais para anéis aromáticos, inclusive evidenciando substituintes oxigenados (grupos hidroxila e metoxila), sinais de olefina e carboxila de amida, bem como sinais para carbono metileno nitrogenado (Tabela 1).

As amidas, como as isoladas neste trabalho, muitas vezes são referidas como alcamidas, e são resultantes da biocondensação de feniletilaminas naturais com ácidos fenilpropânicos. ${ }^{17}$ Todas as amidas citadas acima já foram descritas para outras espécies de Solanum. O processamento do extrato etanólico também possibilitou o isolamento das lignanas: 5-metoxisolariciresinol (5), ${ }^{18}$ polistachiol (9), ${ }^{19}$ (-)-(8S, 7' R,8'R)-9'-O-( $\beta$-D-glicopiranosil)lioniresinol (10) ${ }^{20-21}$ (+)-(8R,7'S,8'S)-9'-O-( $\beta$-D-glicopiranosil)lioniresinol (11),${ }^{20}$ alangilignosideo $\mathrm{C}(\mathbf{1 2}),{ }^{21} \mathrm{e}$ do glicoalcaloide solamargina (13) ${ }^{5}$ 


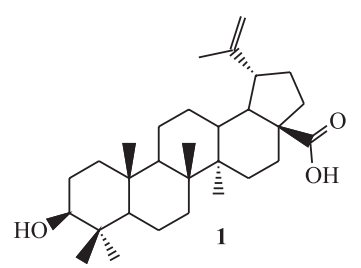

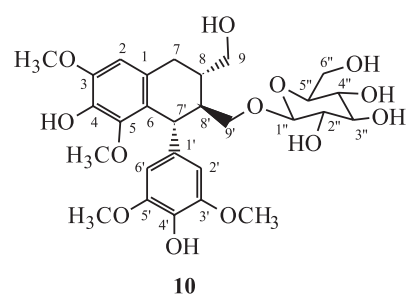<smiles>C=C(CO)C1CC[C@]2(C)C(C)CC(=O)C[C@H]12</smiles>

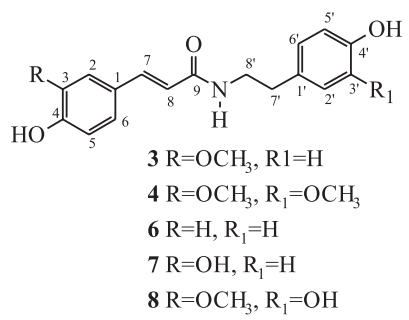<smiles>COc1cc2c(cc1O)[C@H](c1cc(O)c(O)c(OC)c1)[C@H](CO)[C@H](CO)C2</smiles>

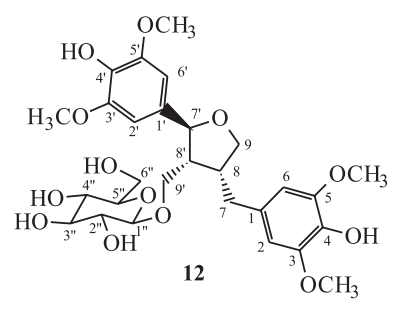<smiles>[R]C[C@H]1[C@@H](CO)Cc2cc(OC)c(O)c([R])c2[C@H]1c1cc(OC)c(O)c(OC)c1</smiles>
$11 \mathrm{R}=\mathrm{OCH}_{3}, \mathrm{R}_{1}=\mathrm{Gli}$ $5 \mathrm{R}=\mathrm{H}, \mathrm{R} 1=\mathrm{H}$

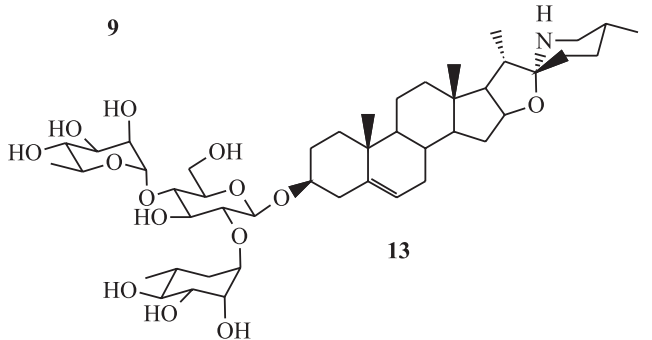

Figura 1. Estruturas das substâncias isoladas dos talos de S. buddleifolium

Os espectros de $\mathrm{RMN}{ }^{1} \mathrm{H}$ e de ${ }^{13} \mathrm{C}$ das lignanas 5, 9-11 mostraram uma estreita semelhança estrutural inclusive com relação aos grupos substituintes, embora $\mathbf{1 0}$ e $\mathbf{1 1}$ tenham apresentado sinais adicionais típicos para unidade de glicose. Nos espectros de RMN de todas elas foram verificados sinais para dois anéis aromáticos substituídos com grupos hidroxilas e metoxilas, além dos sinais característicos das unidades $\mathrm{C}_{3}-\mathrm{C}_{3}$ (representadas pelos carbonos 7, 8, 9 - 7', 8', $\left.9^{\prime}\right)$ de lignanas, os quais aparecem nas faixas de $\delta 33,0$ a 67,0 e 42,0 a 72,0 (Tabela 2). Vale ressaltar que as posições das unidades de glicose em $\mathbf{1 0}$ e $\mathbf{1 1}$ foram determinadas com base nos valores de deslocamentos químicos dos carbonos oximetilênicos C-9', os quais aparecem mais desprotegidos quando comparados com os mesmos carbonos dos compostos análogos 5 e 9 (5: 65,7; 9: 66,9; 10: 71,6 e 11: 71,6), Tabela 2 . Adicionalmente, foram confirmadas com base em experimentos HBMC, através das correlações entre os hidrogênios ligados aos carbonos anoméricos (H-1") de $\mathbf{1 0}$ e 11 em $\delta$ 4,02 e 4,16, respectivamente, com os carbonos oximetilênicos (C-9'), ambos em $\delta 71,6$. A lignana 12, diferentemente das demais, mostrou sinais típicos de lignanas do tipo dihidrofurânicas, cujos sinais de carbonos correspondentes às unidades $\mathrm{C}_{3}-\mathrm{C}_{3}$ aparecem em $\delta 51,8$ a 84,3 e 34,6 a 73,7 (Tabela 2). A localização de todos os substituintes em 12, inclusive da unidade de glicose também foi determinada por experimento HMBC através da correlação entre o sinal de hidrogênio em $\delta 4,30$ (H-1") com o carbono em $\delta 68,6$ (C-9'). As estereoquímicas
Tabela 1. Deslocamentos químicos de $\mathrm{RMN}{ }^{13} \mathrm{C}\left(\mathrm{CD}_{3} \mathrm{OD}, 125 \mathrm{MHz}\right)$ de $\mathbf{3}$, 4,6 - 8

\begin{tabular}{cccccc}
\hline & $\mathbf{3}$ & $\mathbf{4}$ & $\mathbf{6}$ & $\mathbf{7}$ & $\mathbf{8}$ \\
\hline 1 & 128,4 & 128,4 & 127,9 & 128,5 & 128,5 \\
2 & 111,7 & 111,7 & 130,7 & 115,2 & 111,7 \\
3 & 149,4 & 149,9 & 116,9 & 148,9 & 150,0 \\
4 & 149,9 & 149,1 & 160,6 & 146,8 & 149,4 \\
5 & 116,6 & 116,6 & 116,9 & 116,9 & 116,7 \\
6 & 123,4 & 123,4 & 130,7 & 122,2 & 123,4 \\
7 & 142,2 & 142,2 & 141,9 & 142,3 & 142,2 \\
8 & 118,9 & 118,9 & 118,6 & 118,6 & 118,9 \\
9 & 169,3 & 169,4 & 169,4 & 169,4 & 169,4 \\
1 & 131,5 & 132,2 & 131,5 & 131,5 & 132,3 \\
2 & 130,9 & 113,6 & 130,9 & 130,9 & 116,6 \\
3, & 116,4 & 149,4 & 116,4 & 116,4 & 146,5 \\
4 & 157,1 & 146,2 & 157,1 & 157,0 & 144,9 \\
$5^{\prime}$, & 116,4 & 116,3 & 116,4 & 116,4 & 117,1 \\
6' & 130,9 & 122,4 & 130,9 & 130,9 & 121,3 \\
7 & 35,9 & 36,4 & 35,9 & 35,9 & 36,2 \\
8 & 42,7 & 42,6 & 42,7 & 42,7 & 42,7 \\
$\mathrm{H}_{3} \mathrm{CO}-3$ & 56,5 & 56,5 & - & - & 56,6 \\
$\mathrm{H}_{3} \mathrm{CO}-3$ & - & 56,5 & - & - & - \\
\hline & & & & & \\
\hline
\end{tabular}

relativas de todas as lignanas foram determinadas por experimentos de NOESY e NOE seletivo.

Muito embora todas as lignanas isoladas neste trabalho já estejam registradas na literatura, as mesmas estão sendo relatadas pela primeira vez para uma espécie do gênero Solanum. Seus dados de RMN ${ }^{13} \mathrm{C}$ encontram-se dispostos na Tabela 2. A ocorrência de lignanas no gênero Solanum é rara, sendo descrito até o momento apenas para as espécies S. sisymbrifolium, ${ }^{22}$ S. nigrum. ${ }^{23}$ e S. melongena. ${ }^{24}$

Ao longo deste trabalho não foi encontrado nenhum registro ou informação de uso medicinal de S. buddleifolium, mas uma revisão na literatura mostrou que algumas das amidas aqui isoladas exibem atividades farmacológicas. Por exemplo, a amida $N$-trans-feruloiltiramina (3), possui atividade antiviral ${ }^{25} \mathrm{e}$ anti-tumoral, ${ }^{26}$ já o composto $N$-trans$p$-cumaroiltiramina (6) exibe atividade anti-micobacteriana, ${ }^{27}$ enquanto estes compostos juntamente com $N$-trans-cafeoiltiramina (7) eram os constituintes majoritários do extrato $\mathrm{MeOH}$ das partes aéreas de Polygonum hyrcanicum, o qual mostrou-se fortemente ativo contra o Tripanossoma brucei rhodesiense. ${ }^{28}$ Neste contexto, verificou-se que as lignanas, 5-metoxisolariciresinol (5) e (+)-lioniresinol (11) possuem atividade anti-oxidante, ${ }^{29}$ e que a última tambem mostrou-se ativa contra células osteoblásticas. ${ }^{30}$ Isto demonstra o potencial terapêutico das plantas do gênero Solanum como promissoras fontes de compostos ativos, fortalecendo seus usos em medicina tradicional.

\section{PARTE EXPERIMENTAL}

\section{Procedimentos experimentais gerais}

Os espectros no infravermelho foram registrados em espectrômetro da Perkin-Elmer, Spectrum 100 FTIR equipado com assessório UATR. Os espectros de RMN ${ }^{1} \mathrm{He}{ }^{13} \mathrm{C}$, uni- e bidimensionais, foram obtidos em espectrômetro Bruker, modelo Avance DRX-500 (500 MHz para ${ }^{1} \mathrm{H}$ e $125 \mathrm{MHz}$ para ${ }^{13} \mathrm{C}$ ) ou Avance DRX-300 $(300 \mathrm{MHz}$ para ${ }^{1} \mathrm{H}$ e $75 \mathrm{MHz}$ para ${ }^{13} \mathrm{C}$ ). Os espectros de massas de alta resolução 
Tabela 2. Deslocamentos químicos de $\mathrm{RMN}{ }^{13} \mathrm{C}$ de 5, 9-12 $\left(\mathrm{CD}_{3} \mathrm{OD}, 75 \mathrm{MHz}\right)$

\begin{tabular}{|c|c|c|c|c|c|}
\hline & $5 *$ & 9 & 10 & 11 & 12 \\
\hline 1 & 130,5 & 130,3 & 130,3 & 130,3 & 136,0 \\
\hline 2 & 112,8 & 107,9 & 107,9 & 107,9 & 107,1 \\
\hline 3 & 147,2 & 148,7 & 148,8 & 148,8 & 149,3 \\
\hline 4 & 146,4 & 138,9 & 139,0 & 139,0 & 134,9 \\
\hline 5 & 117,9 & 147,8 & 147,7 & 147,7 & 149,3 \\
\hline 6 & 128,2 & 126,3 & 126,5 & 126,5 & 107,1 \\
\hline 7 & 33,7 & 33,6 & 33,9 & 33,9 & 34,6 \\
\hline 8 & 40,4 & 40,9 & 40,7 & 40,7 & 43,9 \\
\hline 9 & 61,9 & 64,3 & 66,3 & 66,3 & 73,7 \\
\hline $1^{\prime}$ & 137,1 & 139,4 & 139,5 & 139,5 & 133,0 \\
\hline $2^{\prime}$ & 107,9 & 106,9 & 107,1 & 107,1 & 104,4 \\
\hline 3 ' & 149,3 & 149,1 & 149,1 & 149,1 & 149,2 \\
\hline 4 ' & 134,3 & 134,6 & 134,6 & 134,6 & 134,9 \\
\hline 5 , & 149,3 & 149,1 & 149,1 & 149,1 & 149,2 \\
\hline $6^{\prime}$ & 107,9 & 106,9 & 107,1 & 107,1 & 104,4 \\
\hline 7 & 48,0 & 49,6 & 42,9 & 42,9 & 84,3 \\
\hline $8^{\prime}$ & 48,6 & 42,4 & 46,8 & 46,8 & 51,8 \\
\hline 9' & 65,7 & 66,9 & 71,6 & 71,6 & 68,6 \\
\hline $1 "$ & - & - & 104,9 & 104,9 & 104,8 \\
\hline $2 "$ & - & - & 75,3 & 75,3 & 75,2 \\
\hline $3 "$ & - & - & 78,4 & 78,4 & 78,2 \\
\hline $4 "$ & - & - & 71,8 & 71,8 & 71,7 \\
\hline $5 "$ & - & - & 78,0 & 78,0 & 78,0 \\
\hline $6 "$ & - & - & 62,9 & 62,9 & 62,8 \\
\hline $\mathrm{H}_{3} \mathrm{CO}-3$ & - & 60,2 & 60,3 & 60,3 & 56,8 \\
\hline $\mathrm{H}_{3} \mathrm{CO}-5$ & 56,2 & 56,7 & 56,7 & 56,7 & 56,8 \\
\hline $\mathrm{H}_{3} \mathrm{CO}-3$ & 56,3 & 56,8 & 56,9 & 56,9 & 56,8 \\
\hline $\mathrm{H}_{3} \mathrm{CO}-5$ & 56,3 & 56,8 & 56,9 & 56,9 & 56,8 \\
\hline
\end{tabular}

* Deslocamentos químicos de $\mathrm{RMN}{ }^{13} \mathrm{C}$ de 5 em piridina $\left(\mathrm{C}_{6} \mathrm{D}_{5} \mathrm{~N}\right)$.

foram realizados em espectrômetro mod. LCMS-IT-TOF (225-0710034) - SHIMADZU, equipado com fonte de ionização por electrospray. A separação de alguns dos compostos foi realizada em cromatógrafo líquido de alta eficiência da Shimadzu-UFLC com detector UV-Vis com arranjo de diodos modelo FTD-M20A empregando coluna semi-preparativa Phenomenex (C-18, $250 \times 10 \mathrm{~mm})$, com partículas de $5 \mu \mathrm{m}$. Nas cromatografias de adsorção utilizou-se gel de sílica 60 da Vetec ( $\varnothing \mu \mathrm{m}$ 70-230 mesh, para cromatografias gravitacionais) e Merck ( “flash"), enquanto nos fracionamentos cromatográficos por exclusão molecular foi empregado Sephadex LH-20 (Pharmacia). As cromatografias em camada delgada analítica (CCDA) foram realizadas com gel de sílica 60, ( $\varnothing \mu \mathrm{m}$ 5-40, Merck) com indicador de fluorescência na faixa de $254 \mathrm{\eta m}\left(\mathrm{F}_{254}\right)$, sobre cromatofolha de sílica gel sobre alumínio. As substâncias foram reveladas pela exposição a vapores de iodo, ou pela aspersão de uma solução de vanilina/ácido perclórico/ $\mathrm{EtOH}$, seguida de aquecimento em estufa $\left(\approx 100{ }^{\circ} \mathrm{C}\right)$, ou ainda por imersão em Dragendorff.

\section{Material vegetal}

S. buddleifolium foi coletado no município de Piatã-BA em dezembro de 2009. A autenticação do material vegetal foi realizada pela Prof ${ }^{a}$. Lenise Guedes do Instituto de Biologia - UFBA. Uma exsicata ( $\mathrm{n}^{\circ}$ 16395), representando a coleta da planta encontra-se depositada no Herbário Prisco Bezerra (EAC) da Universidade Federal do Ceará.

\section{Extração e isolamento}

Os talos $(2,0 \mathrm{Kg})$ de $S$. buddleifolium, secos a temperatura ambiente e triturados, foram submetidos à percolação com EtOH $96 \%$ ( 3 x 8 L). Após evaporação do solvente, sob pressão reduzida, foram obtidos $100,0 \mathrm{~g}$ de extrato (5\% em relação ao peso seco). $\mathrm{O}$ extrato $\mathrm{EtOH}$ foi dissolvido em $\mathrm{MeOH} / \mathrm{H}_{2} \mathrm{O}$ (7:3) e particionado com hexano, $\mathrm{CH}_{2} \mathrm{Cl}_{2}$ e AcOEt $(3$ x $200 \mathrm{~mL}$ de cada solvente). As frações obtidas, depois de reunidas, foram secas com $\mathrm{Na}_{2} \mathrm{SO}_{4}$ anidro, filtradas e concentradas sob pressão reduzida fornecendo as seguintes massas: hexano (5,3 g), $\mathrm{CH}_{2} \mathrm{Cl}_{2}$ (7,1 g) e AcOEt-1 (6,1 g). O resíduo proveniente da fase aquosa foi acidificado com uma solução de $\mathrm{H}_{2} \mathrm{O}$ / $\mathrm{AcOH}$ (90:10 $100 \mathrm{~mL}$ ) e mantido sob agitação por 1h. Decorrido este período a mistura reacional foi basificada com $\mathrm{NH}_{4} \mathrm{OH}$ até $\mathrm{pH} 10,0$ e posteriormente particionado com AcOEt $(3 \times 100 \mathrm{~mL})$ e $\mathrm{n}-\mathrm{BuOH}$ $(2 \times 40 \mathrm{~mL})$. As frações obtidas foram secas com $\mathrm{Na}_{2} \mathrm{SO}_{4}$ anidro, filtradas e concentradas sob pressão reduzida, fornecendo 1,5 e $8,1 \mathrm{~g}$ de material, respectivamente. A fração $\mathrm{CH}_{2} \mathrm{Cl}_{2}(7,1 \mathrm{~g})$ foi submetida a fracionamento sobre gel de sílica, empregando os solventes hexano, AcOEt e $\mathrm{MeOH}$, puros ou em gradiente de polaridade crescente. Foram coletadas 20 frações de $50 \mathrm{~mL}$, as quais, após monitoramento em CCD, foram agrupadas em 4 frações (A-I a A-IV). A fração A-I (719,5 mg), obtida por eluição com hexano/AcOEt (1:1) foi submetida a sucessivas cromatografias, fornecendo os esteroides $\beta$-sitosterol e estigmasterol (30,0 mg), em mistura, e 1 (16,5 mg). A-II (913,9 $\mathrm{mg}$ ), após sucessivos fracionamentos cromatográficos, conduziu ao isolamento da substância 2 (17,1 mg), cuja purificação foi realizada por cromatografia "flash", empregando como eluente $\mathrm{CH}_{2} \mathrm{Cl}_{2} / \mathrm{MeOH}$ (99:1). A-III (1,2 g), foi fracionada em gel de sílica utilizando como eluentes hexano, AcOEt e $\mathrm{MeOH}$, puros ou em gradiente de polaridade crescente, fornecendo 4 frações principais (B1 a B4), após monitoramento em CCD. B3 (706,8 mg), obtida por eluição com AcOEt (100\%), foi submetida a cromatografia de exclusão molecular utilizando Sephadex LH-20 e MeOH como fase móvel, obtendo-se 5 frações (C-1 a C-5), após monitoramento por CCD. As frações C-2 (96,4 mg), C-3 (293,6 mg) e C-4 (107,5 mg), foram submetidas a cromatografia líquida de alta eficiência (CLAE), utilizando coluna semipreparativa C-18 (4,6 x $250 \mathrm{~mm}, 5 \mu \mathrm{m})$, um sistema isocrático de $\mathrm{H}_{3} \mathrm{CCN} /\left(\mathrm{H}_{2} \mathrm{O}+0,1 \%\right.$ TFA) (3:7) e, fluxo de $4,72 \mathrm{~mL} / \mathrm{min}$. com detecção na faixa de 210 a $350 \mathrm{~nm}$. Este procedimento resultou no isolamento das substâncias $\mathbf{3}\left(t_{R} 9,37 ; 17,0 \mathrm{mg}\right), \mathbf{4}\left(t_{R} 10,33 ; 8,0 \mathrm{mg}\right) \mathrm{e}$ $5\left(t_{R} 7,68 ; 7,0 \mathrm{mg}\right)$, a partir de C-2; $6\left(t_{R} 8,46 \mathrm{~min} ; 18,6 \mathrm{mg}\right)$, isolada da fração C-3, enquanto 7 ( $\left.t_{R} 5,93 \mathrm{~min} ; 27,8 \mathrm{mg}\right)$ e $8\left(t_{R} 6,44 \mathrm{~min} ; 6,8\right.$ $\mathrm{mg}$ ) foram obtidas da fração C-4. A fração A-IV $(3,4 \mathrm{~g})$ foi fracionada em Sephadex LH-20 utilizando $\mathrm{MeOH}$ como eluente, resultando em 25 frações de $10 \mathrm{~mL}$ que, após análise em $\mathrm{CCD}$, foram reunidas em 4 frações (D-1 a D-4). A fração D-4 (1,5 g) foi recromatografada em Sephadex LH-20, utilizando MeOH como sistema de eluição, obtendo 4 novas frações denominadas de (E-1 a E-4). A fração E-3 (1,0 g) foi posteriormente, submetida à cromatografia "flash", utilizado como eluente AcOEt/MeOH aumentando a polaridade até $10 \%$ de $\mathrm{MeOH}$, resultando em 85 frações $(\sim 8,0 \mathrm{~mL})$ as quais, após monitoramento em CCD, foram reunidas em 5 frações codificadas como (F-1 a F-5). A fração F-4 (19,0 mg), apresentou-se como um sólido branco amorfo caracterizado como sendo a mistura dos esteroides $\beta$-sitosterol e estigmasterol na sua forma glicosilada. A fração F-5 (415,5 mg) foi submetida a fracionamento em cartucho-SPE de fase reversa $\left(\mathrm{C}_{18}\right)$ empregando como sistemas de eluição $\mathrm{H}_{2} \mathrm{O} / \mathrm{MeOH}(1: 1,3: 7$ e 0:10) 
gerando 20 frações de $10 \mathrm{~mL}$ cada, as quais após monitoramento por CCD foram reunidas em 3 frações denominadas de (G-1 a G-3). A fração G-1 (320,0 mg), foi submetida a CLAE utilizando um sistema isocrático de $\mathrm{MeOH} / \mathrm{H}_{2} \mathrm{O}$ (4:6), com fluxo de 4,72 $\mathrm{mL} / \mathrm{min}$, fornecendo 3 picos. A fração correspondente ao pico $1\left(t_{R} 5,18 ; 50,0 \mathrm{mg}\right)$ foi reinjetada utilizando desta vez o sistema isocrático de $\mathrm{H}_{3} \mathrm{CCN} /$ $\mathrm{H}_{2} \mathrm{O}$ (18:82), com fluxo de $4,72 \mathrm{~mL} / \mathrm{min}$, resultando na purificação da substância $12\left(t_{R} 16,0 ; 8,3 \mathrm{mg}\right)$. A fração AcOEt-B (1,5 g), obtida da partição após neutralização, foi fracionada em Sephadex LH-20, utilizando $\mathrm{MeOH}$ como eluente, gerando 25 frações de $10 \mathrm{~mL}$ que, após análise em $\mathrm{CCD}$, foram reunidas em 4 frações designadas F-1 a F-4. A fração F-2 (536,8 mg) foi recromatografada em Sephadex LH-20, utilizando-se $\mathrm{MeOH}$, culminando em 5 frações denominadas (G-1 a G-5). A fração G-3 (314,0 mg) foi submetida a cromatografia em coluna de fase reversa C-18 empregando como sistema de eluição $\mathrm{H}_{2} \mathrm{O} / \mathrm{MeOH}(2: 8,3: 7,6: 4,5: 5$ e 0:10), fornecendo 60 frações de 10 $\mathrm{mL}$ que após analise em CCD foram reunidas em 3 frações (H-1 a H-3). A fração H-1 (230,0 mg) foi purificada por CLAE usando um sistema isocrático de $\mathrm{MeOH} /\left(\mathrm{H}_{2} \mathrm{O}+0,3 \%\right.$ de TFA) (27:73) com fluxo de 4,72 $\mathrm{mL} / \mathrm{min}$ fornecendo as substâncias: $\mathbf{1 0}\left(t_{R} 15,13 ; 30,0 \mathrm{mg}\right), \mathbf{1 1}$ $\left(t_{R} 16,83 ; 16,0 \mathrm{mg}\right)$ e $\mathbf{9}\left(t_{R} 18,57 ; 7,0 \mathrm{mg}\right)$. A fração H-3 $(309,5 \mathrm{mg})$ foi submetida a cromatografia em coluna de fase reversa $\mathrm{C}_{18}$ empregando como sistema de eluição $\mathrm{H}_{2} \mathrm{O} / \mathrm{MeOH}$ (7:3, 5:5 e 0:10), obtendo-se 30 frações de $10 \mathrm{~mL}$ que, após monitoramento por $\mathrm{CCD}$, foram reunidas em 3 frações designadas (I-1 a I-3), a fração I-3 (58,0 mg) foi purificada por CLAE empregando um sistema isocrático de $\mathrm{H}_{3} \mathrm{CCN} /$ $\mathrm{H}_{2} \mathrm{O}(2: 8)$ com fluxo de $4,72 \mathrm{~mL} / \mathrm{min}$, obtendo-se a substância $\mathbf{1 3}$ $\left(t_{R} 15,13 ; 30,0 \mathrm{mg}\right.$, P.F. $\left.278-280{ }^{\circ} \mathrm{C}\right)$.

$N$-trans-feruloiltiramina (3) resina incolor, 17,0 mg, EMAR-IES, $m / z$ 336, 1216, $[\mathrm{M}+\mathrm{Na}]^{+}, \mathrm{C}_{18} \mathrm{H}_{19} \mathrm{NNaO}_{4}$ (massa calc. 336,1212). RMN ${ }^{1} \mathrm{H} \mathrm{e}^{13} \mathrm{C}\left(500\right.$ e $125 \mathrm{MHz}$ em CD $\left.\mathrm{CD}_{3} \mathrm{OD}\right)$ em acordo com a literatura. ${ }^{14,15}$

N-trans-feruloil-3'-O-metoxidopamina (4) sólido amorfo, 7,0 mg, P.F. $155-157^{\circ} \mathrm{C}$, EMAR-IES, $m / z$ 366,1309, $[\mathrm{M}+\mathrm{Na}]^{+}, \mathrm{C}_{19} \mathrm{H}_{21} \mathrm{NNaO}_{5}$ (massa calc. 366,1317). $\mathrm{RMN}{ }^{1} \mathrm{He} \mathrm{e}^{13} \mathrm{C}(500$ e $125 \mathrm{MHz}$ em CD $\mathrm{OD}$ ) em acordo com a literatura. ${ }^{16}$

(+)-(8R,7'S, 8'S)-5-metoxisolariciresinol (5) resina, 7,0 mg, $[\alpha]_{\mathrm{D}}{ }^{25}+9,25(\mathrm{MeOH}$, conc. 0,12$)$, lit. ${ }^{20}[\alpha]_{\mathrm{D}}+43,1(\mathrm{MeOH}$, conc. 0,20). EMAR-IES, $m / z, 413,1573,[\mathrm{M}+\mathrm{Na}]^{+}, \mathrm{C}_{21} \mathrm{H}_{26} \mathrm{O}_{7} \mathrm{Na}$ (massa calc. 413,1576$)$. $\mathrm{RMN}^{1} \mathrm{He} \mathrm{e}^{13} \mathrm{C}\left(300\right.$ e $75 \mathrm{MHz}$ em $\left.\mathrm{C}_{5} \mathrm{D}_{5} \mathrm{~N}\right)$ em acordo com a literatura. ${ }^{18}$

$N$-trans-p-cumaroiltiramina (6) sólido amorfo, 18,6 mg, P.F. 235-237 ${ }^{\circ} \mathrm{C}$, EMAR-IES, $\mathrm{m} / z$, 306,1116, [M+Na $]^{+}, \mathrm{C}_{17} \mathrm{H}_{17} \mathrm{NNaO}_{3}$ (massa calc. 306,1106). RMN ${ }^{1} \mathrm{H} \mathrm{e}^{13} \mathrm{C}\left(500\right.$ e $125 \mathrm{MHz}$ em CD $\left.\mathrm{CD}_{3} \mathrm{OD}\right)$ em acordo com a literatura. ${ }^{13,14}$

$\mathrm{N}$-trans-cafeoiltiramina (7) sólido amorfo, 27,8 mg, P.F. 208-210 ${ }^{\circ} \mathrm{C}$, EMAR-IES, $\mathrm{m} / z$ 322,1053, $[\mathrm{M}+\mathrm{Na}]^{+}, \mathrm{C}_{17} \mathrm{H}_{17} \mathrm{NNaO}_{4}$ (massa calc. 322,1055). $\mathrm{RMN}{ }^{1} \mathrm{He} \mathrm{e}^{13} \mathrm{C}\left(500\right.$ e $125 \mathrm{MHz}$ em CD $\mathrm{CD}_{3}$ ) em acordo com a literatura. ${ }^{12}$

$N$-trans-feruloildopamina (8) sólido amorfo, 6,8 mg, P.F. 128-130 ${ }^{\circ} \mathrm{C}$, EMAR-IES, $m / z$ 352,1159, $[\mathrm{M}+\mathrm{Na}]^{+}, \mathrm{C}_{18} \mathrm{H}_{19} \mathrm{NNaO}_{5}$ (massa calc. 352,1161). RMN ${ }^{1} \mathrm{He}^{13} \mathrm{C}\left(500\right.$ e $125 \mathrm{MHz}$ em $\left.\mathrm{CD}_{3} \mathrm{OD}\right)$ em acordo com a literatura. ${ }^{13}$

Polistachiol (9) resina incolor, 7,0 $\mathrm{mg},[\alpha]_{\mathrm{D}}^{25}-2,50^{\circ}(\mathrm{MeOH}$; conc. 0,10$)$, lit. ${ }^{22}[\alpha]_{\mathrm{D}}{ }^{22} \sim 0$ (MeOH, conc. 1,0). EMAR-IES, $m / z$, 420,1764, [M+Na] ${ }^{+}, \mathrm{C}_{21} \mathrm{H}_{26} \mathrm{O}_{7} \mathrm{Na}$ (massa calc. 420,1710). $\mathrm{RMN}{ }^{1} \mathrm{He}$ ${ }^{13} \mathrm{C}$ (300 e $75 \mathrm{MHz}$ em $\mathrm{CD}_{3} \mathrm{OD}$ ) em acordo com a literatura. ${ }^{19}$
(-)-( $\left.8 S, 7^{\prime} R, 8^{\prime} R\right)-9^{\prime}-O$ - $(\beta$-D-glicopiranosil)-lioniresinol (10) resina, 30,0 mg, $[\alpha]_{\mathrm{D}}^{25}-10,30^{\circ}(\mathrm{MeOH}$; conc. 0,10$)$, lit. $^{23,24}[\alpha]_{\mathrm{D}}$ $-105^{\circ}\left(\mathrm{MeOH}\right.$; conc. 1,2). EMAR-IES, $\mathrm{m} / \mathrm{z}$ 605,2200, $[\mathrm{M}+\mathrm{Na}]^{+}$, $\mathrm{C}_{28} \mathrm{H}_{38} \mathrm{O}_{13} \mathrm{Na}$, (massa calc. 605,2210). $\mathrm{RMN}{ }^{1} \mathrm{He} \mathrm{e}^{13} \mathrm{C}(300$ e $75 \mathrm{MHz}$ em $\left.\mathrm{CD}_{3} \mathrm{OD}\right)$ em acordo a literatura. ${ }^{20}$

(+)-(8R,7'S, 8'S)-9'-O-( $\beta$-D-glicopiranosil)-lioniresinol (11) resina, 16,0 mg, $[\alpha]_{\mathrm{D}}{ }^{25}+19,46^{\circ}(\mathrm{MeOH}$; conc. 0,10$)$, lit. ${ }^{23,24}[\alpha]_{\mathrm{D}}$ $+61^{\circ}\left(\mathrm{MeOH}\right.$; conc. 2,20). EMAR-IES, $\mathrm{m} / z$ 605,2200, $[\mathrm{M}+\mathrm{Na}]^{+}$, $\mathrm{C}_{28} \mathrm{H}_{38} \mathrm{O}_{13} \mathrm{Na}$ (massa calc. 605,2210). $\mathrm{RMN}{ }^{1} \mathrm{H} \mathrm{e}{ }^{13} \mathrm{C}(300$ e $75 \mathrm{MHz}$ em $\mathrm{CD}_{3} \mathrm{OD}$ ) em acordo com a literatura. ${ }^{20}$

Alangilignosideo $C$ (12) sólido amorfo amarelo, 8,0 mg, P.F. 138$140{ }^{\circ} \mathrm{C}$, lit. ${ }^{25}$ P.F. $168-170{ }^{\circ} \mathrm{C} ;[\alpha]_{\mathrm{D}}{ }^{25}+1,40^{\circ}(\mathrm{MeOH}$, conc. 0,10$)$, lit. ${ }^{25}$ $[\alpha]_{\mathrm{D}}{ }^{24}+16.2^{\circ}(\mathrm{MeOH}$, conc. 0,74). EMAR-IES, $m / z$ 605,2198, $[\mathrm{M}+$ $\mathrm{Na}]^{+}, \mathrm{C}_{28} \mathrm{H}_{38} \mathrm{O}_{13} \mathrm{Na}$, (massa calc. 605,2210). $\mathrm{RMN}{ }^{1} \mathrm{He} \mathrm{e}^{13} \mathrm{C}$ (300 e 75 $\mathrm{MHz}$ em $\mathrm{CD}_{3} \mathrm{OD}$ ) em acordo com a literatura. ${ }^{21}$

\section{MATERIAL SUPLEMENTAR}

As Figuras $1 \mathrm{~S}$ à $33 \mathrm{~S}$ estão disponíveis em http://quimicanova. sbq.org.br, em arquivo pdf, com acesso livre.

\section{CONCLUSÃO}

O estudo fitoquímico do extrato etanólico de talos de $S$. buddleifolium conduziu ao isolamento de vários metabólitos secundários de natureza terpênica e fenólica, comuns em espécies de Solanum. Entretanto, contrariando as expectativas, foi isolado apenas um alcalóide esteroidal pertencente ao grupo de compostos considerados como marcadores quimiotaxonômico. S. buddleifolium mostrou-se como uma prolífica fonte de amidas e lignanas.

\section{AGRADECIMENTOS}

Às agencias brasileiras de fomento a pesquisa CNPq/CAPES/ PRONEX/FUNCAP e INCT-NanoBioSimes, pelo auxilio financeiro concedido para a realização deste trabalho, bem como as bolsas de estudo e de pesquisa.

\section{REFERÊNCIAS}

1. Morais, M. S.; Braz-Filho, R.; Produtos naturais: estudos químicos e biológicos, EdUECE: Fortaleza, 2007.

2. Braz-Filho, R.; Quim. Nova. 2010, 33, 229.

3. Friedman, M.; J. Chromatogr. A 2004, 1054, 143.

4. Torres, M. C. M.; Pinto, F. C. L.; Pessoa, O. D. L.; Silveira, E. R.; Braz-Filho, R.; Jorge, R. J. B.; Ximenes, R. M.; Monteiro, H. S. A.; Evangelista, J. S. A. M.; Diz-Filho, E. B. S.; Toyama, M. H.; J. Nat. Prod. 2011, 74, 2168.

5. Pinto, F. C. L.; Silva, F. M.; Theodoro, P. N. E. T.; Uchoa, D. E. A.; Espíndola, L. S.; Pessoa, O. D. L.; Silveira, E. R.; Braz-Filho, R.; Quim. Nova. 2011, 34, 284.

6. Maia, A. I. V.; Veras, M. L.; Braz-Filho, R.; Lopes, N. P.; Silveira, E. R.; Pessoa, O. D. L.; J. Braz. Chem. Soc. 2010, 21, 867.

7. Silva, T. M. S.; Nascimento, R. J. B.; Batista, M. M.; Agra, M. F.; Camara, C. A.; Rev. Bras. Farmacogn. 2007, 17, 35.

8. Nurit, K.; Agra, M. F.; Basílio, I. J. L. D.; Rev. Bras. Bioc. 2007, 5, 243.

9. Silva, H. R.; Silva, C. C. M.; Neto, L. B. C.; Lopes, J. A. D.; Citó A. M. G. L.; Chaves, M. H.; Quim. Nova. 2007, 30, 1877.

10. David, J. M.; Souza, J. C.; Guedes, M. L. S.; David, J. P.; Rev. Bras. Farmacogn. 2006, 16, 105. 
11. Nagaoka, T.; Goto, K.; Watanabe, A.; Sakata, Y.; Yoshihara, T.; $J$. Biosciences 2001, 56, 181.

12. Silva, T. M. S.; Nascimento, R. J. B.; Camara, C. A.; Castro, R.; Agra, M. F.; Carvalho, M. G.; Braz-Filho, R.; Biochem. Syst. Ecol. 2004, 32, 513; Kim, D. K.; Lim, J. P.; Kim, J. W.; Park, H. W.; Eun, J. S.; Arch. Pharmacal Res. 2005, 28, 39.

13. Zacarés, L.; López-Gresa, M. P.; Fayos, J.; Primo, J.; Bellés, J. M.; Conejero, V.; Mol. Plant-Microbe Interact. 2007, 20, 1439.

14. Shu, W.; Zhou, G.; Ye, W.; Zhongcaoyao 2011, 42, 424.

15. Kanada, R. M.; Simionato, J. I.; Arruda, R. F.; Santin, S. M. O.; Souza, M. C.; Silva, C. C.; Rev. Bras. Farmacogn. 2012, 22, 502.

16. Tanaka, H.; Yatsuhashi, Saya.; Yasuda, T.; Sato, M.; Sakai, E.; Xiao, C.; Murata, H.; Murata, J.; Journal of Natural Medicines 2009, 63, 331; Ren, Y.; Shen, L.; Dai, S.; Zhongguo Zhongyao Zazhi 2009, 34, 721.

17. Back, K.; Plant Pathol. J. 2001, 17, 123.

18. Zhang, Z.; Guo, D.; Li, C.; Zheng, J.; Koike, K.; Jia, Z.; Nikaido, T.; Phytochemistry 1999, 51, 469; Chin, Y. W.; Chai, H. B.; Keller, W. J.; Kinghorn, A. D.; J. Agric. Food Chem. 2008, 56, 7759.

19. Sadhu, S. K.; Phattanawasin, P.; Choudhuri, M. S. K. ; Ohtsuki, T.; Ishibashi, M.; Journal of Natural Medicines 2006, 60, 258.

20. Da Silva, V. C.; Silva, G. H.; Bolzani, V. S.; Lopes, M. N.; Ecletica Quim. 2006, 31, 55; Sun, G.; Zhang, X.; Xu, X.; Yang, J.; Lu, L.; Zhong, M.; J. Med. Plants Res. 2012, 6, 2200.
21. Yuasa, K.; Ide, T.; Tsuka,; H. Ogimi, C.; Hirata, E.; Takushi, A.; Takeda, Y.; Phytochemistry 1997, 45, 611.

22. Chakravarty, A. K.; Mukhopadhyay, S.; Saha, S.; Pakrash, S. C. A.; Phytochemistry 1996, 41, 935.

23. Zhao, Y.; Liu, F.; Lou, H. X. J. Chin. Med. Mat. 2010, 33, 555; Wang, L. Y.; Wang, N. L.; Yao, X. S.; J. Chin. Med. Mat. 2007, 30, 792.

24. Liu, X.; Luo, J.; Kong, L.; J. Nat. Prod. 2011, 6, 851.

25. Wang, R.; Tang, S.; Zhai, H.; Duan, H.; Zhongguo Zhongyao Zazhi 2011, 36, 1032

26. Fang, J.; Liu, Y.; Zhang, Y.; Teng, J.; Duan, H.; Zhongcaoyao 2007, 38, 976.

27. Mata, R.; Morales, I.; Perez, O.; Rivero-Cruz, I.; Acevedo, L.; EnriquezMendoza, I.; Bye, R.; Franzblau, S.; Timmermann, B.; J. Nat. Prod. 2004, 67, 1961.

28. Moradi-Afrapoli, F.; Yassa, N.; Zimmermann, S.; Saeidnia, S.; Hadjiakhoondi, A.; Ebrahimi, S. N.; Hamburger, M.; Nat. Prod. Commun. 2012, 7,753 .

29. Huang, X. Z.; Cheng. C. M.; Dai, Y.; Fu, G. M.; Guo, J. M.; Liang, H.; Wang, C.; Nat. Prod. Res. 2012, 26, 1876.

30. Van, K. P.; Quang, T. H.; Huong, T. T.; Nhung, L. T. H.; Cuong, N. X.; Van, M. C.; Choi, E. M.; Kim, Y. H.; Arch. Pharmacal Res. 2008, 31, 823. 


\section{CONSTITUINTES QUÍMICOS DE Solanum buddleifolium SENDTN}

Francisco das Chagas L. Pinto, Maria da Conceição M. Torres, Edilberto R. Silveira e Otília Deusdênia L. Pessoa*

Departamento de Química Orgânica e Inorgânica, Centro de Ciências, Universidade Federal do Ceará, CP 12.200, 60021-940 Fortaleza - CE, Brasil

\section{Raimundo Braz-Filho}

Departamento de Química, Universidade Estadual do Norte Fluminense, 28013-602 Campos - RJ, Brasil

Maria Lenise da Silva Guedes

Departamento de Botânica, Instituto de Biologia, Universidade Federal da Bahia, 40170-115, Campus Universitário de Ondina - BA, Brasil

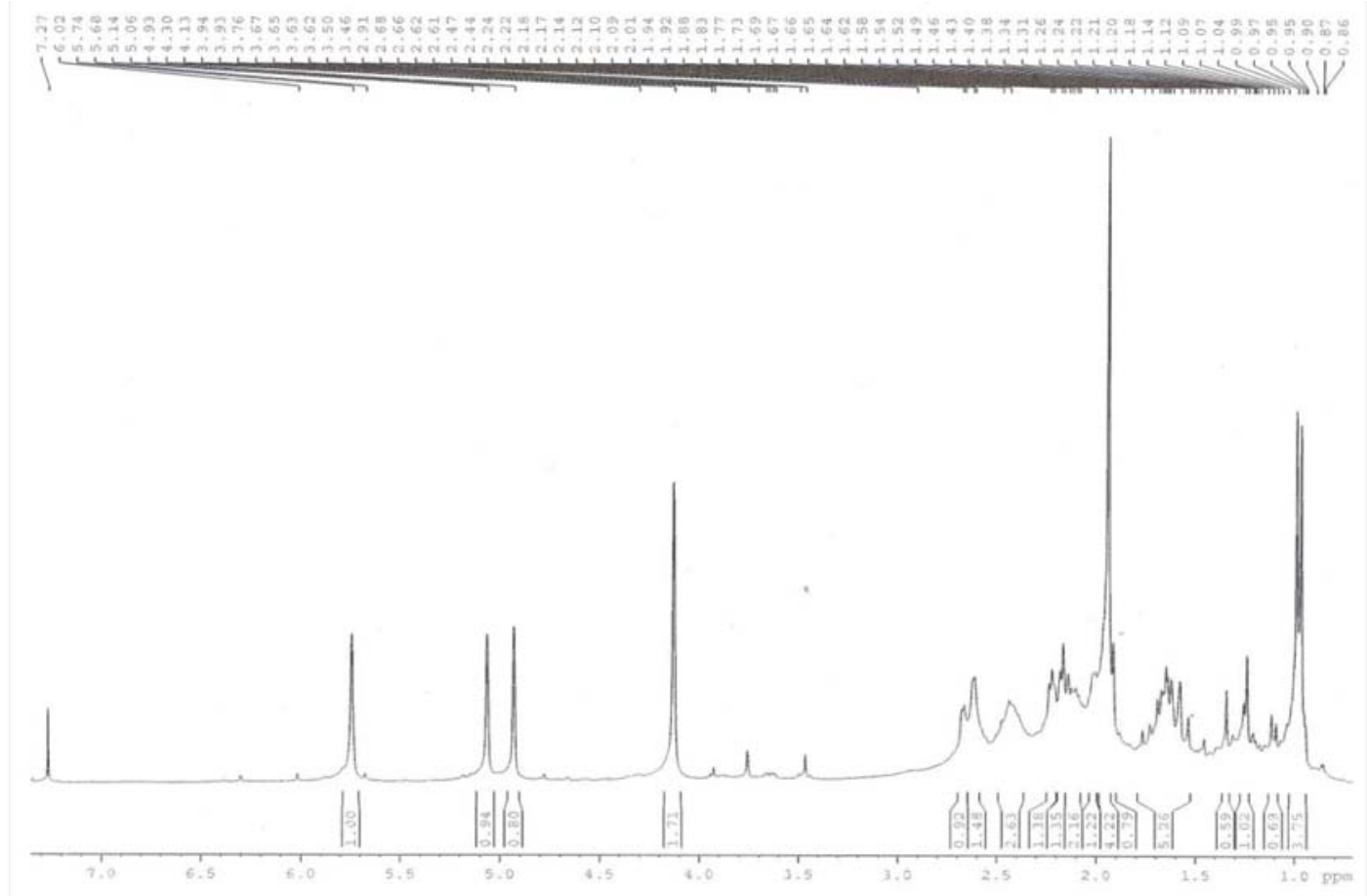

Figura 1S. Espectro de $\mathrm{RMN}^{1} \mathrm{H}\left(300 \mathrm{MHz}, \mathrm{CDCl}_{3}\right)$ de 2 


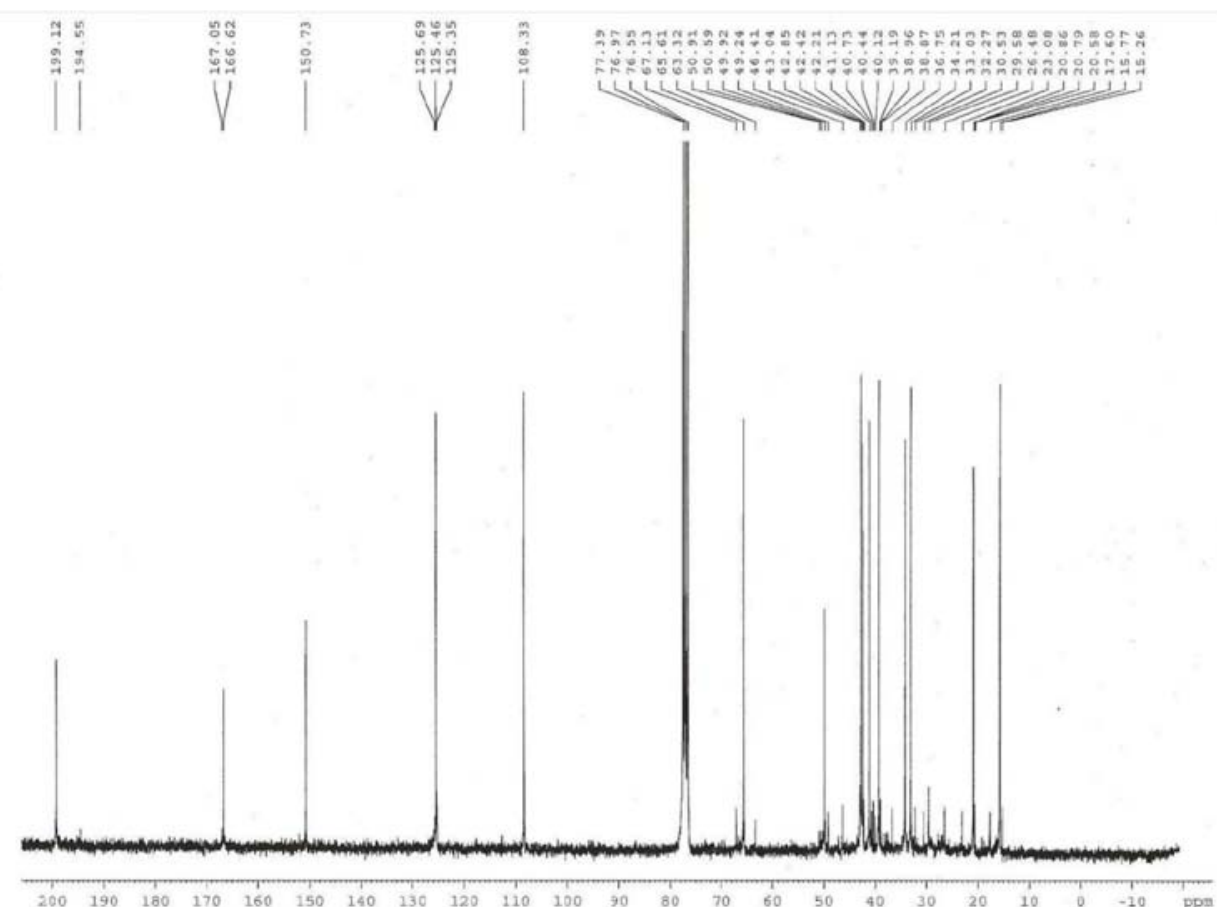

Figura 2S. Espectro de $\mathrm{RMN}^{13} \mathrm{C}\left(75 \mathrm{MHz}, \mathrm{CDCl}_{3}\right)$ de 2

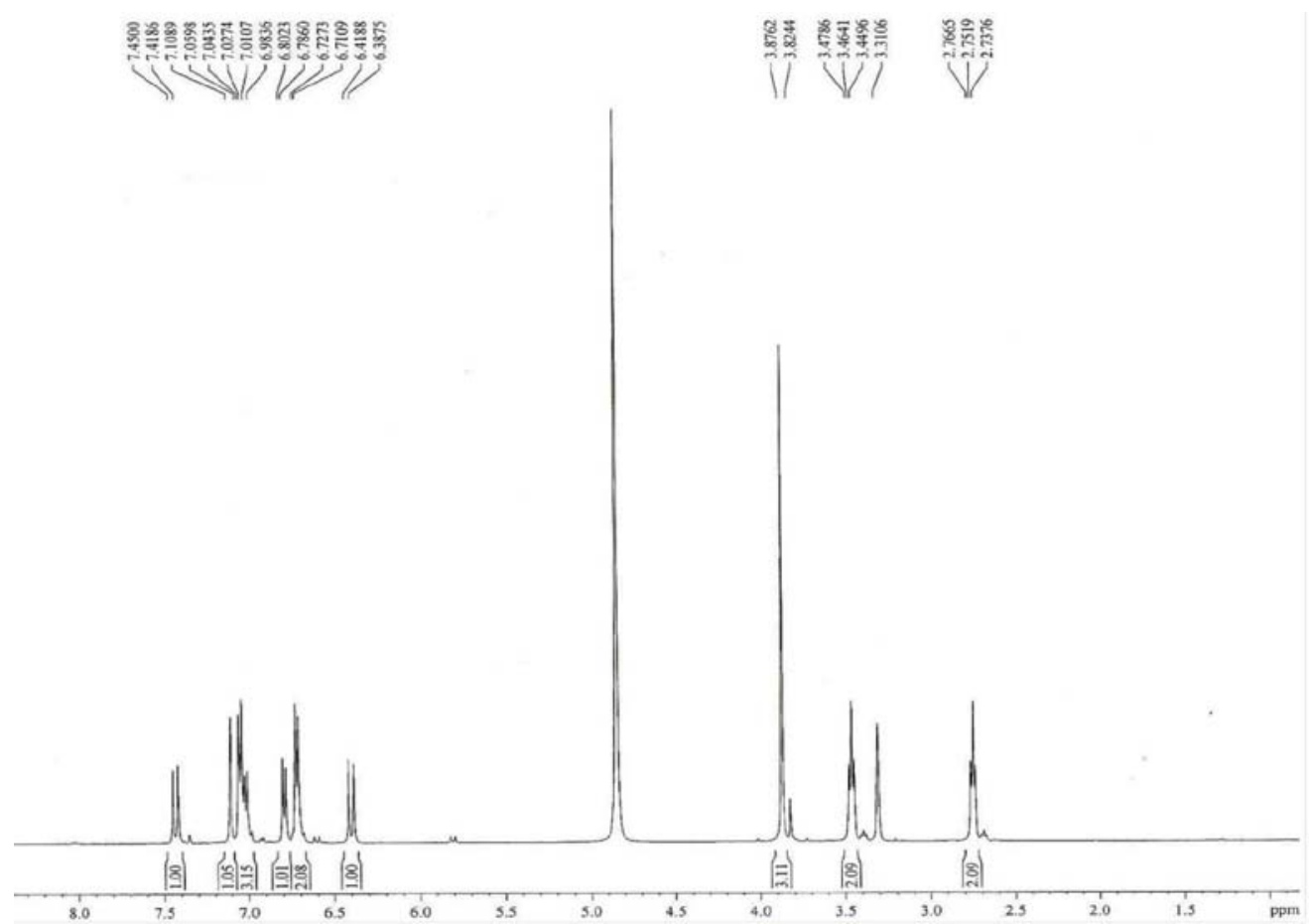

Figura 3S. Espectro de $\mathrm{RMN}^{1} \mathrm{H}\left(500 \mathrm{MHz}, C D_{3} \mathrm{OD}\right)$ de 3 


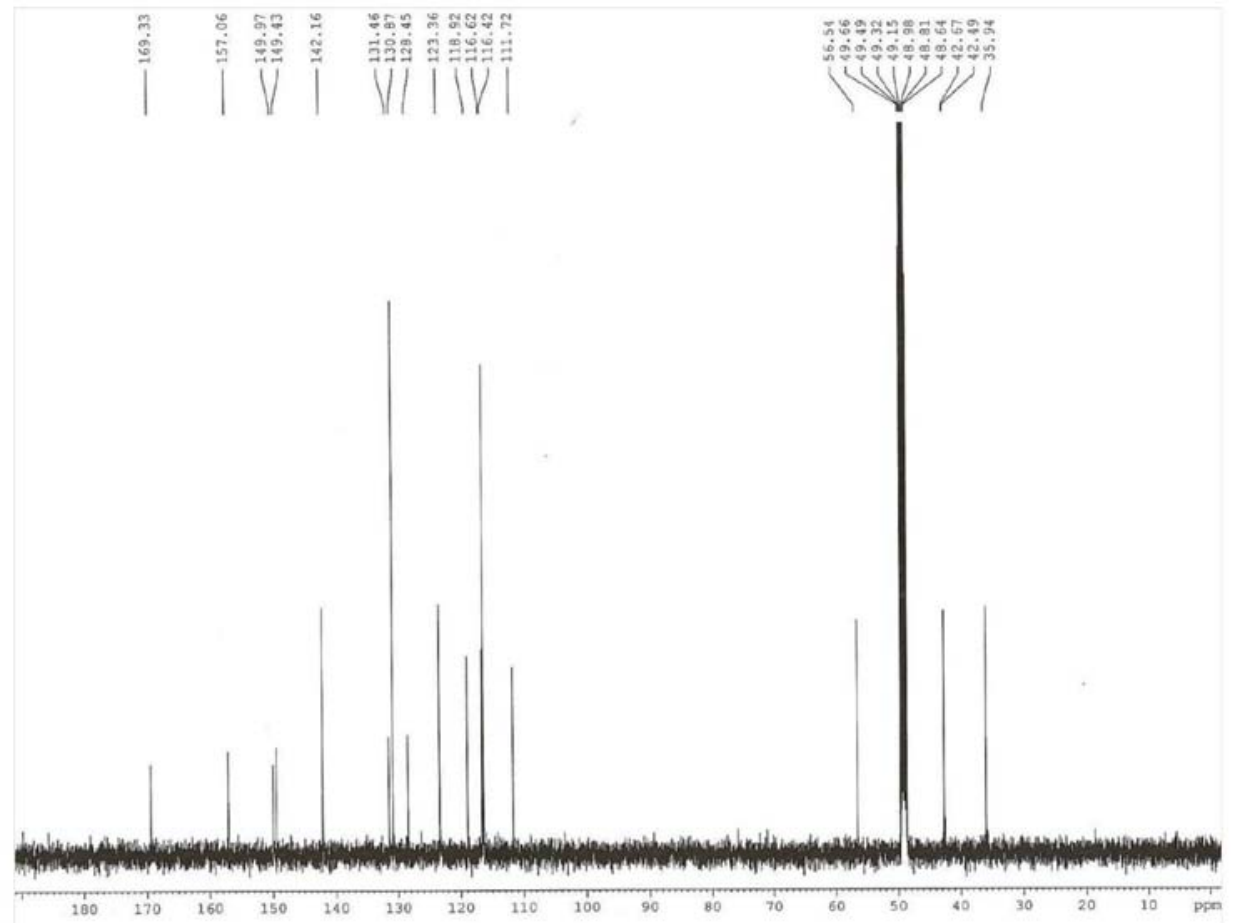

Figura 4S. Espectro de $\mathrm{RMN}^{13} \mathrm{C}\left(125 \mathrm{MHz}, \mathrm{CD}_{3} \mathrm{OD}\right)$ de 3

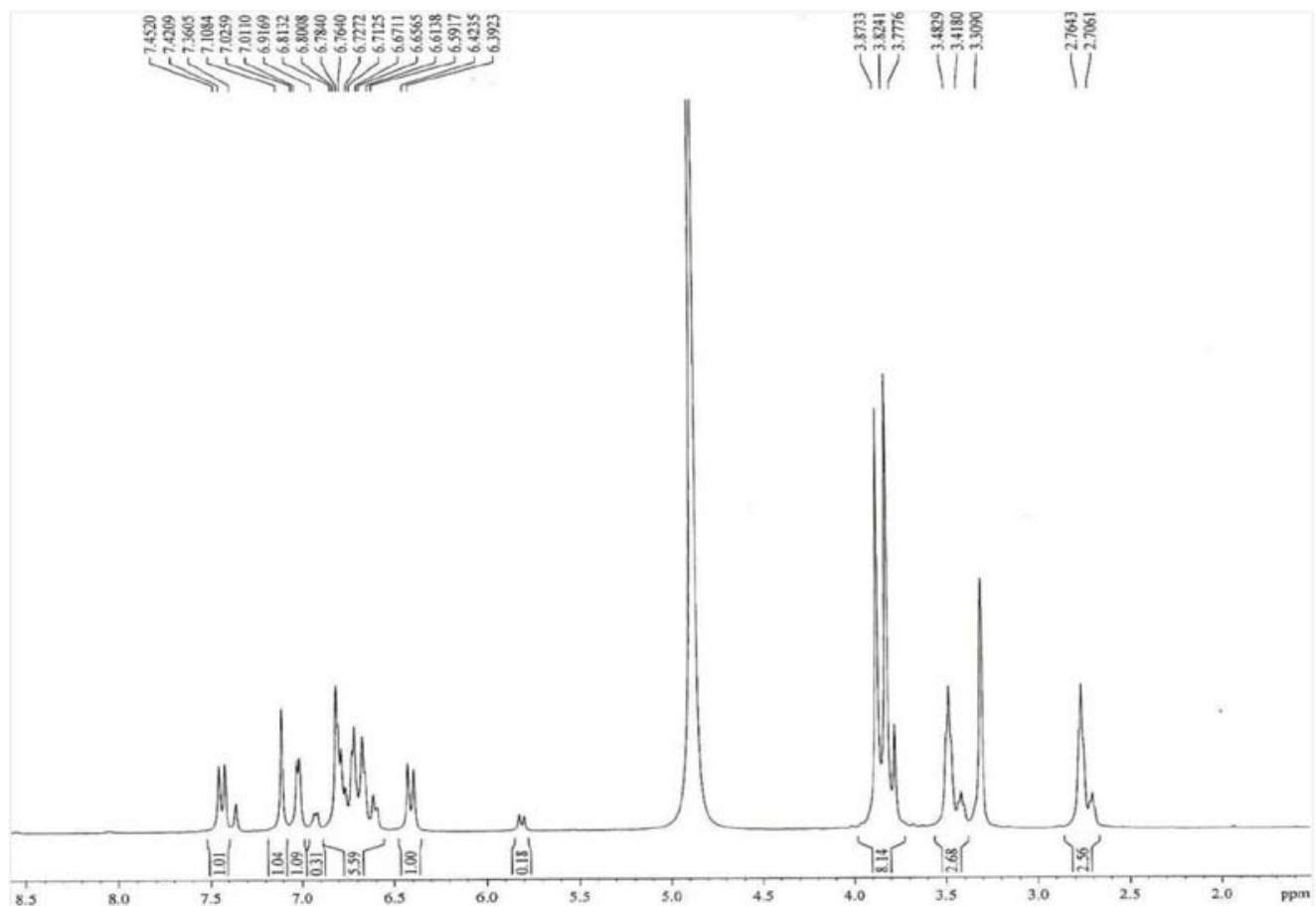

Figura 5S. Espectro de $\mathrm{RMN}^{1} \mathrm{H}\left(500 \mathrm{MHz}, \mathrm{CD}_{3} \mathrm{OD}\right) \mathrm{de} 4$ 
S4

Pinto et al.

Quim. Nova

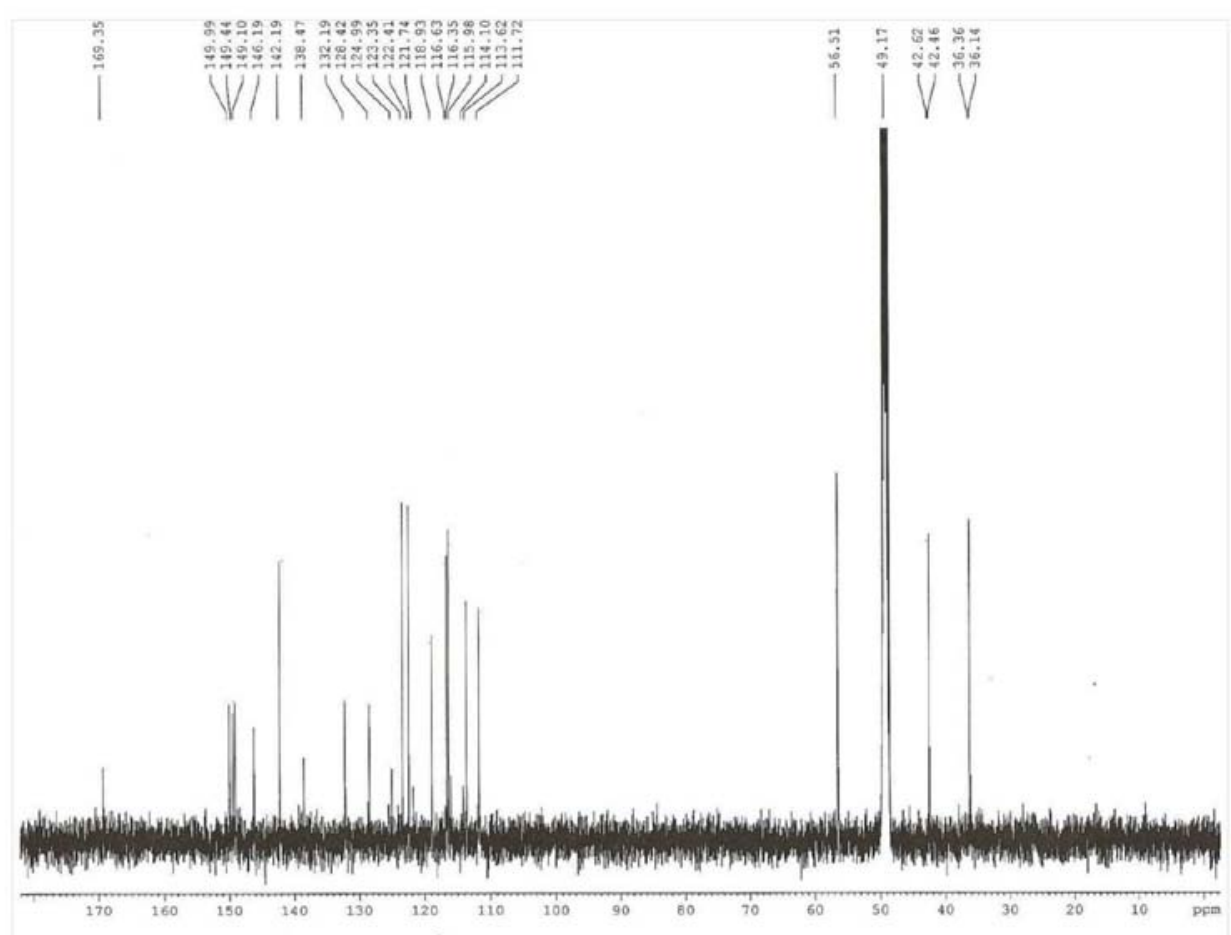

Figura 6S. Espectro de $R M N{ }^{13} \mathrm{C}\left(125 \mathrm{MHz}, C D_{3} \mathrm{OD}\right)$ de 4

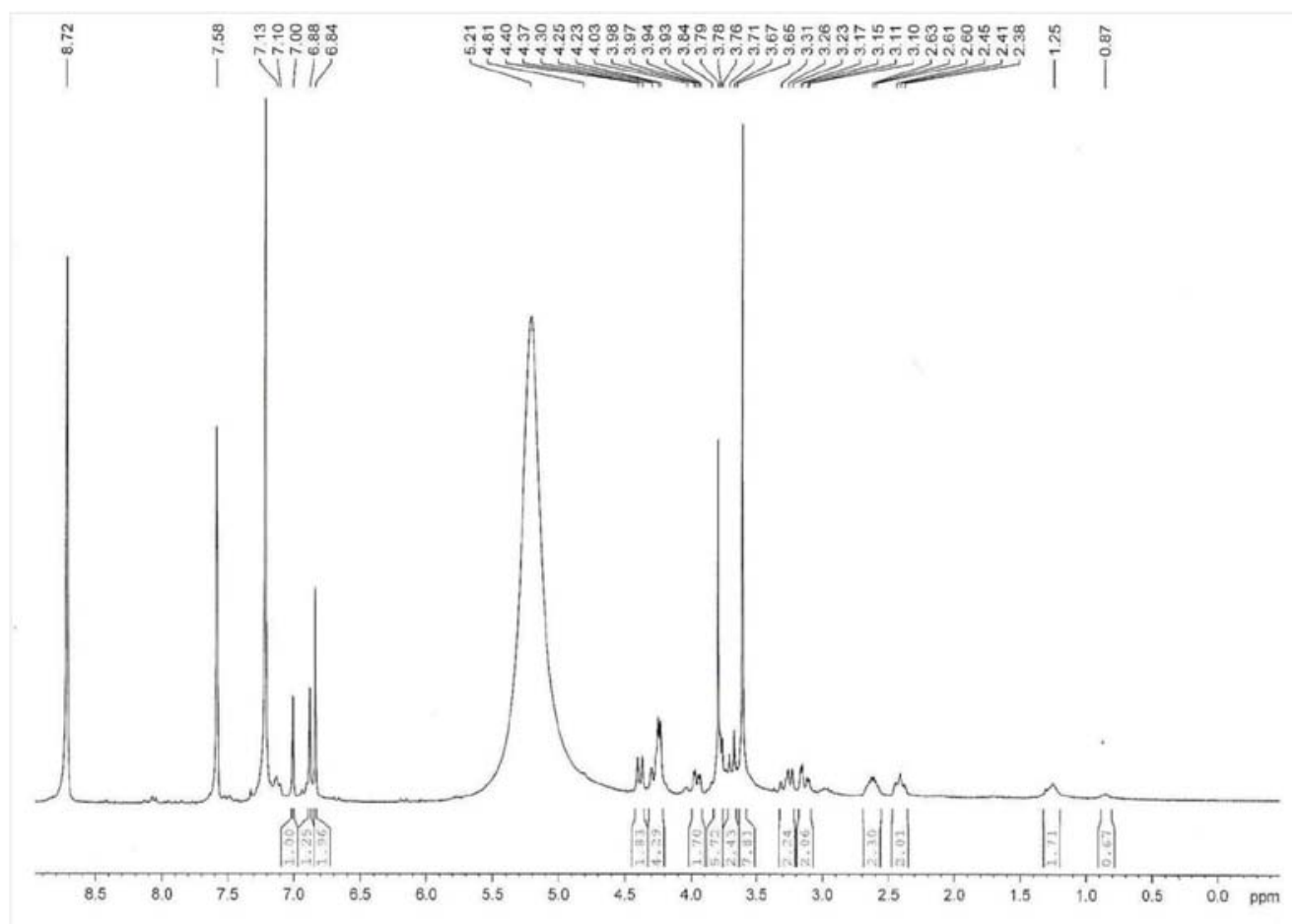

Figura 7S. Espectro de $R M N^{l} H\left(300 \mathrm{MHz}, C_{5} D_{5} N\right)$ de 5 


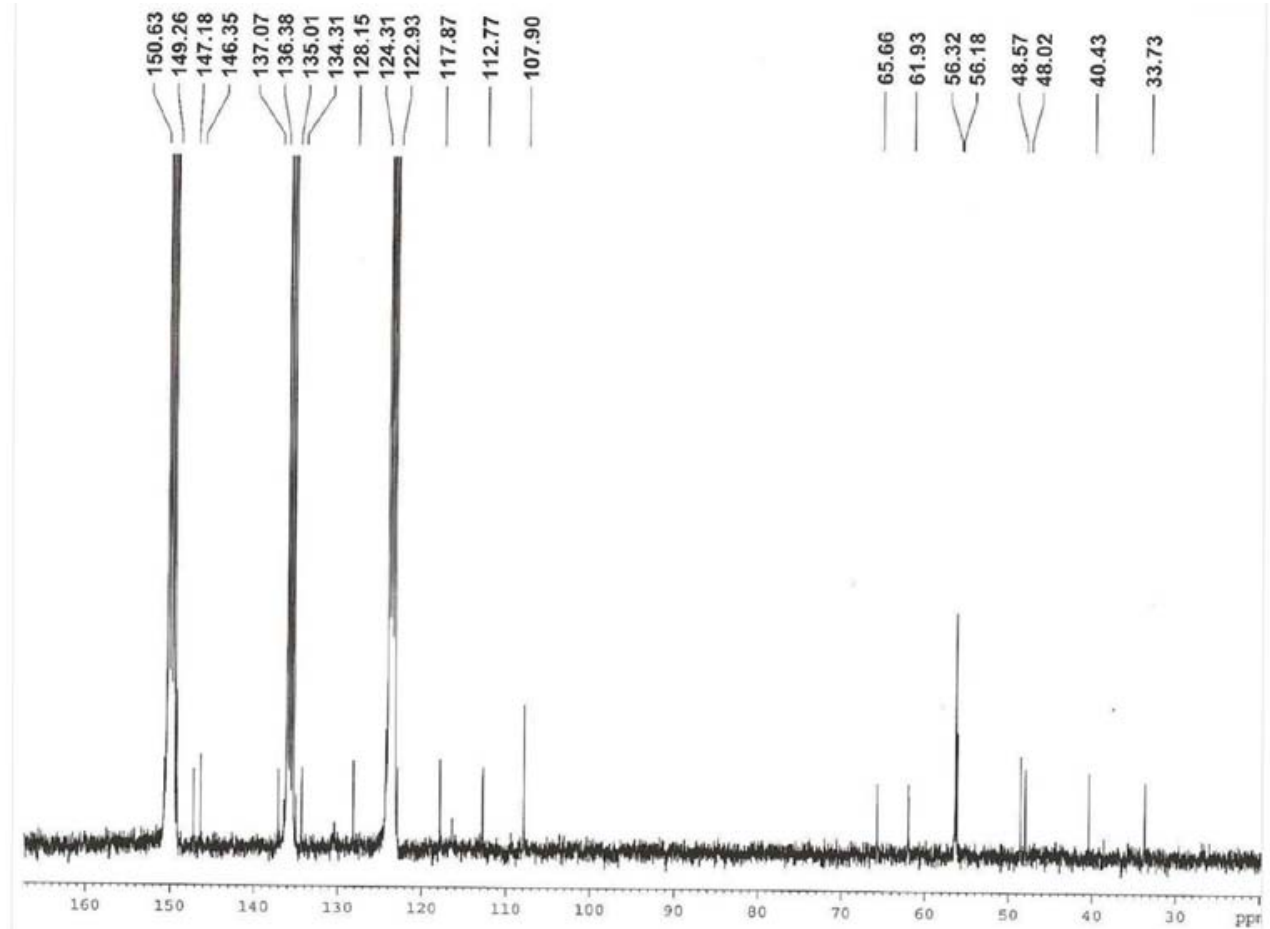

Figura 8S. Espectro de $R M N{ }^{13} \mathrm{C}\left(75 \mathrm{MHz}, \mathrm{C}_{5} D_{5} \mathrm{~N}\right)$ de 5

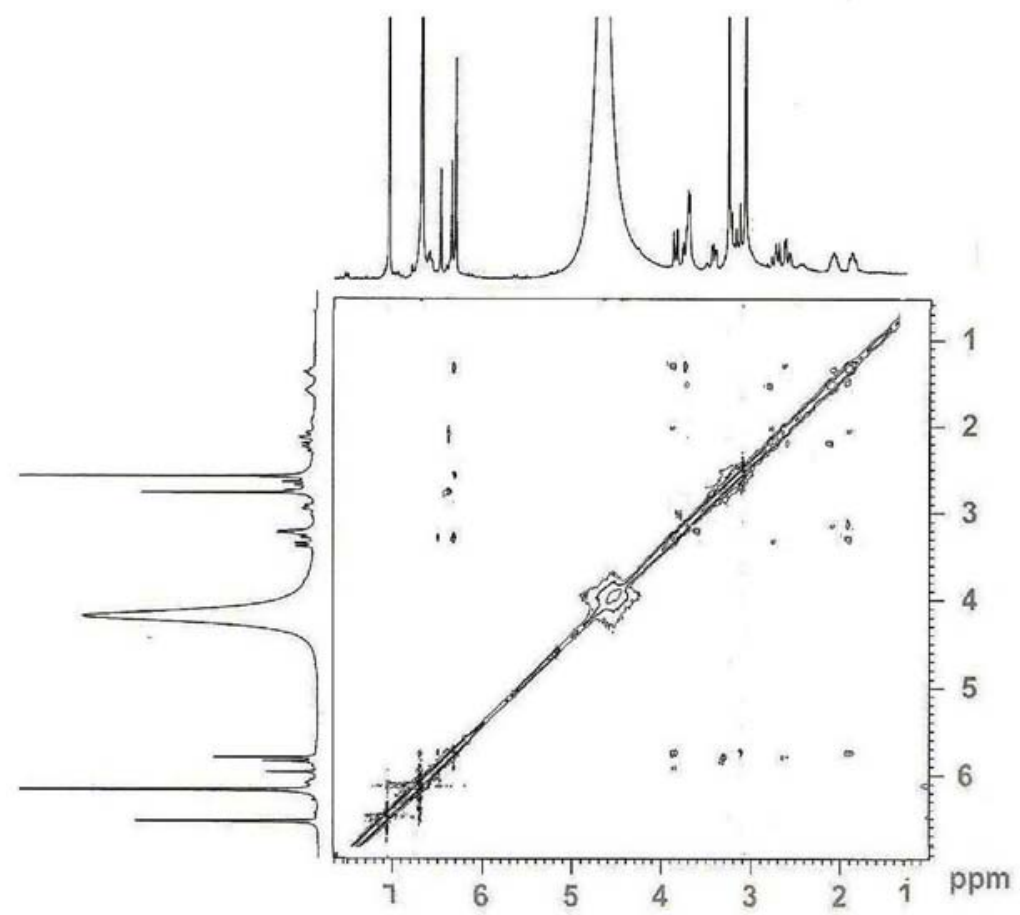

Figura 9S. Espectro de $\mathrm{RMN}{ }^{l} \mathrm{H},{ }^{l} \mathrm{H} \mathrm{NOESY}\left(300 \times 300 \mathrm{MHz}, \mathrm{C}_{5} \mathrm{D}_{5} \mathrm{~N}\right)$ de 5 


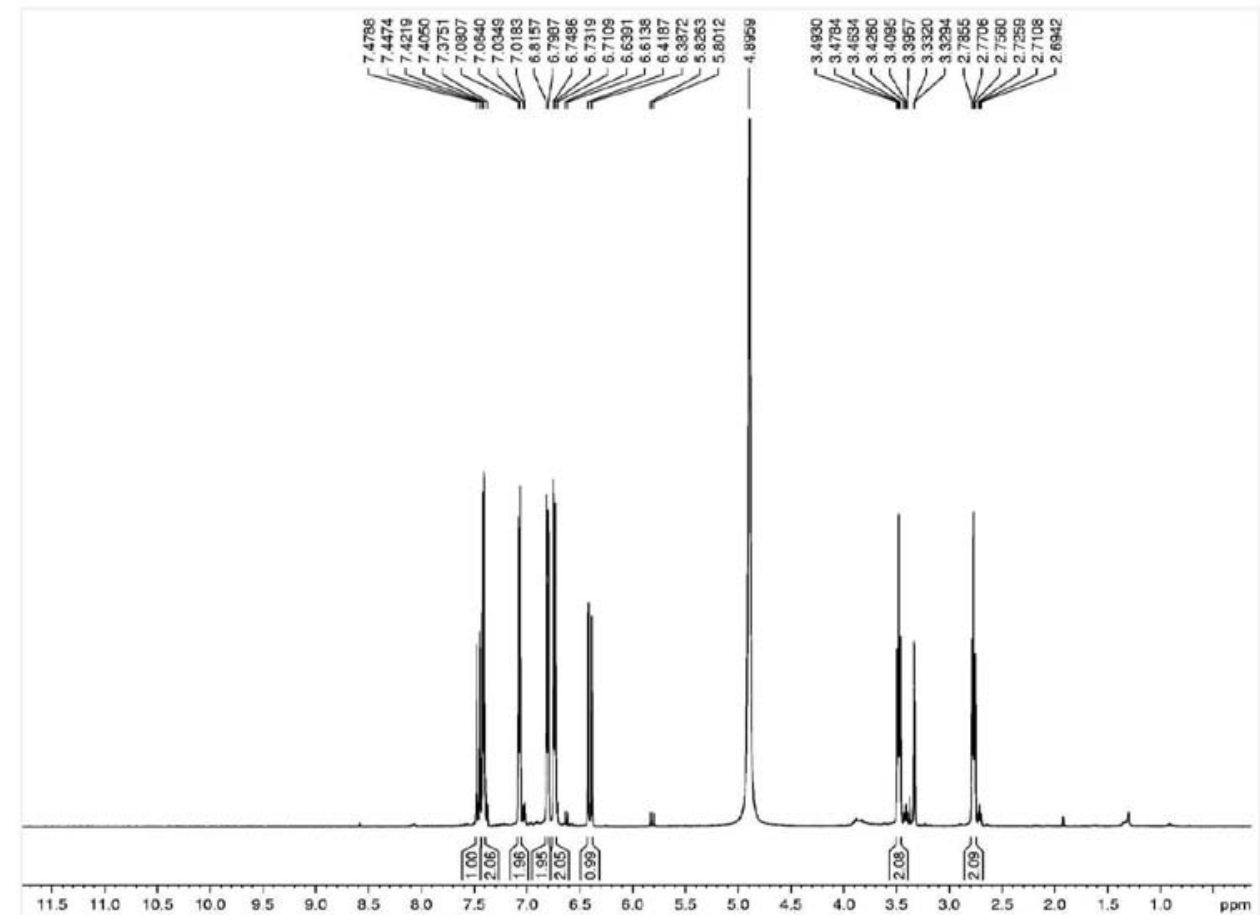

Figura 10S. Espectro de $R M N^{1} \mathrm{H}\left(500 \mathrm{MHz}, C D_{3} \mathrm{OD}\right)$ de 6

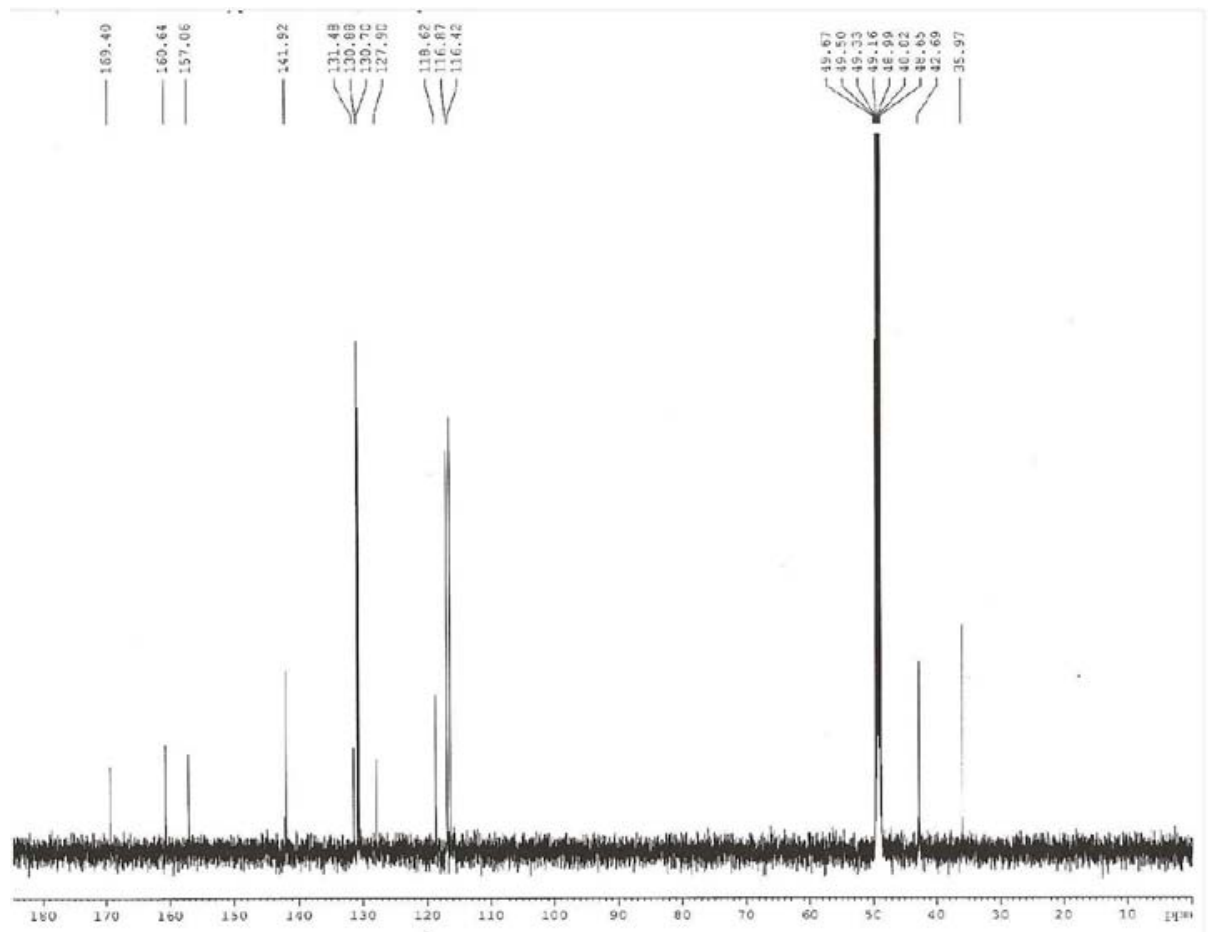

Figura 11S. Espectro de $\mathrm{RMN}^{13} \mathrm{C}\left(125 \mathrm{MHz}, \mathrm{CD}_{3} \mathrm{OD}\right)$ de 6 


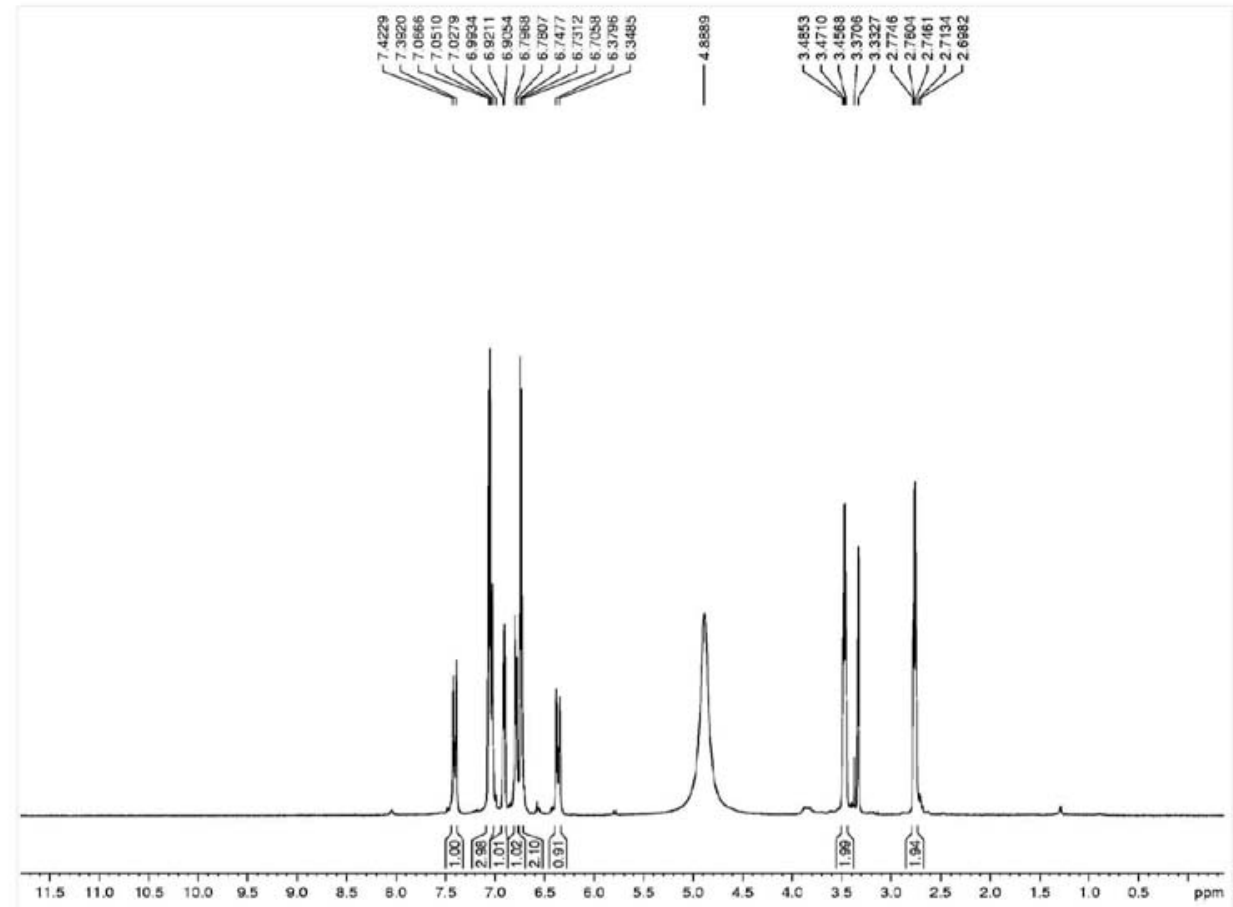

Figura 12S. Espectro de $\mathrm{RMN}^{1} \mathrm{H}\left(500 \mathrm{MHz}, C D_{3} \mathrm{OD}\right)$ de 7

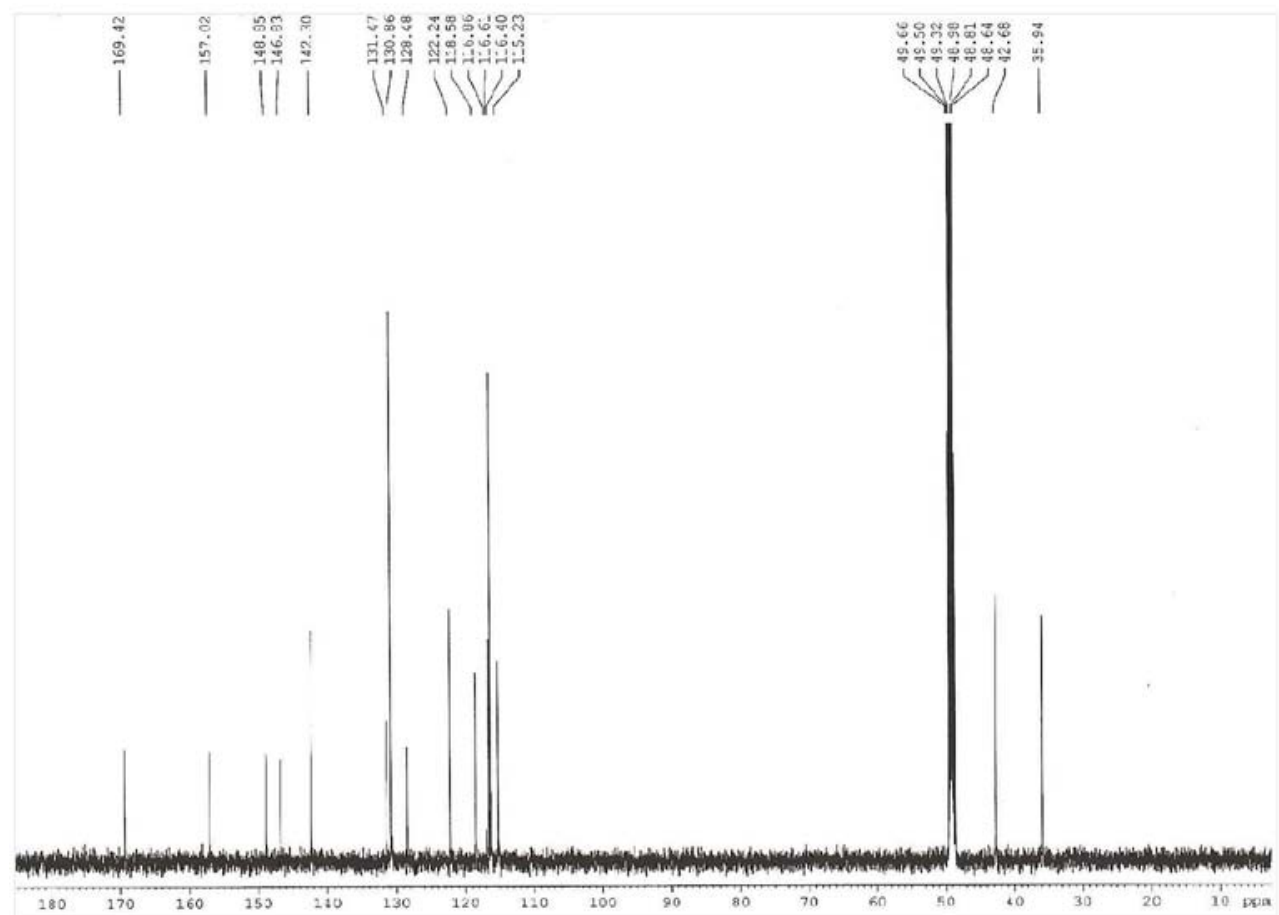

Figura 13S. Espectro de $R M N^{13} \mathrm{C}\left(125 \mathrm{MHz}, C D_{3} \mathrm{OD}\right)$ de 7 


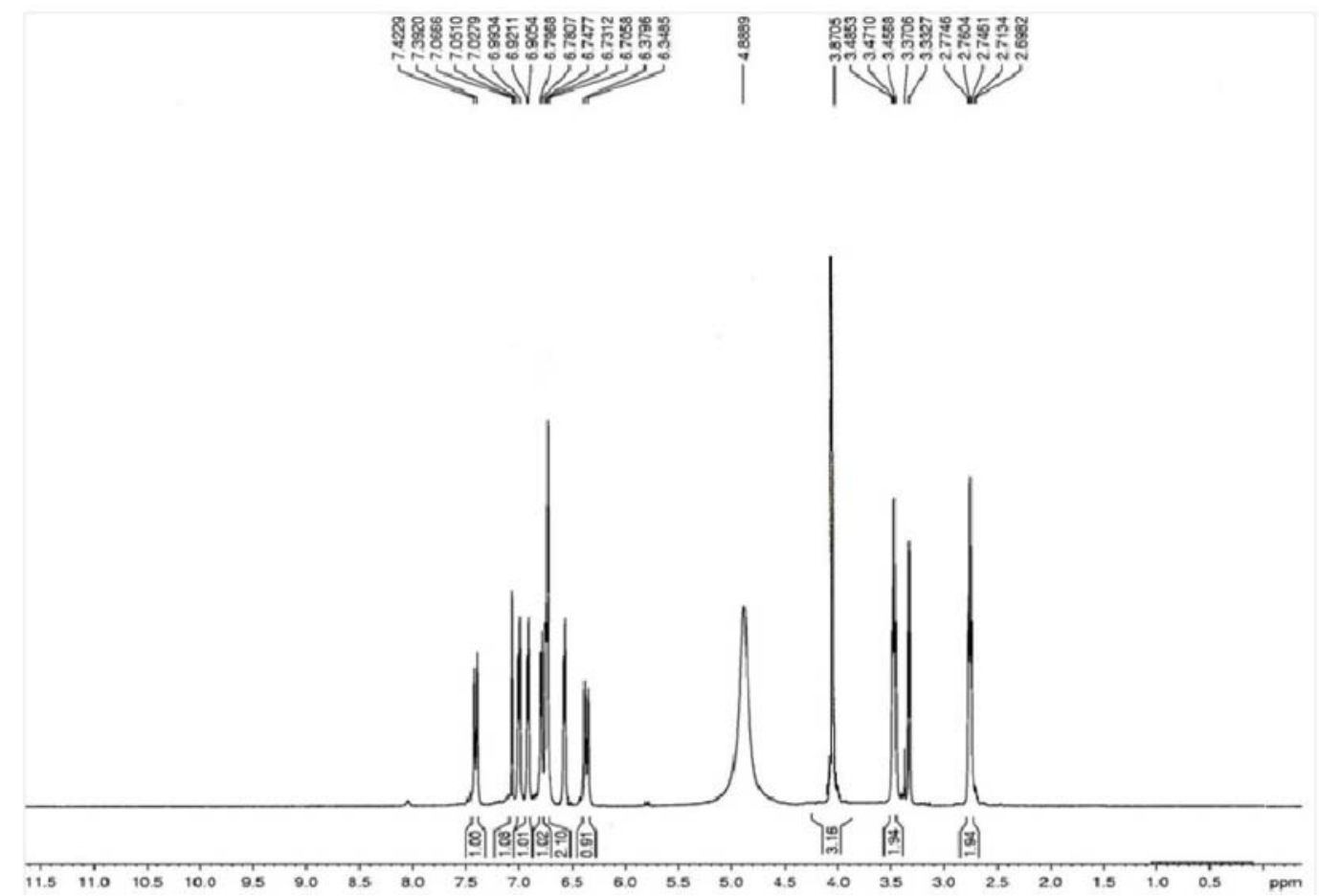

Figura 14S. Espectro de $R M N^{l} \mathrm{H}\left(500 \mathrm{MHz}, C D_{3} \mathrm{OD}\right)$ de 8

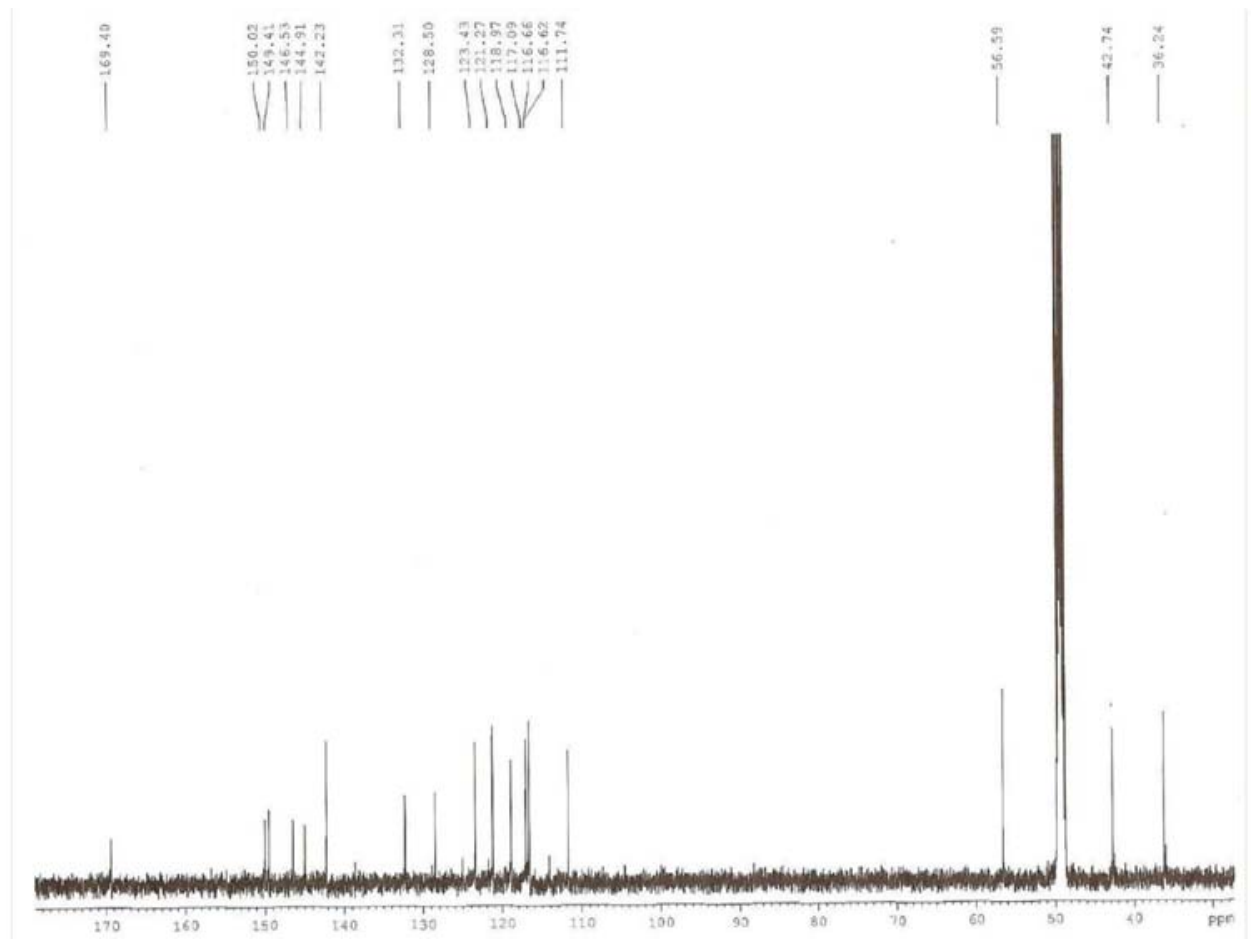

Figura 15S. Espectro de $\mathrm{RMN}^{13} \mathrm{C}\left(125 \mathrm{MHz}, \mathrm{CD}_{3} \mathrm{OD}\right)$ de 8 


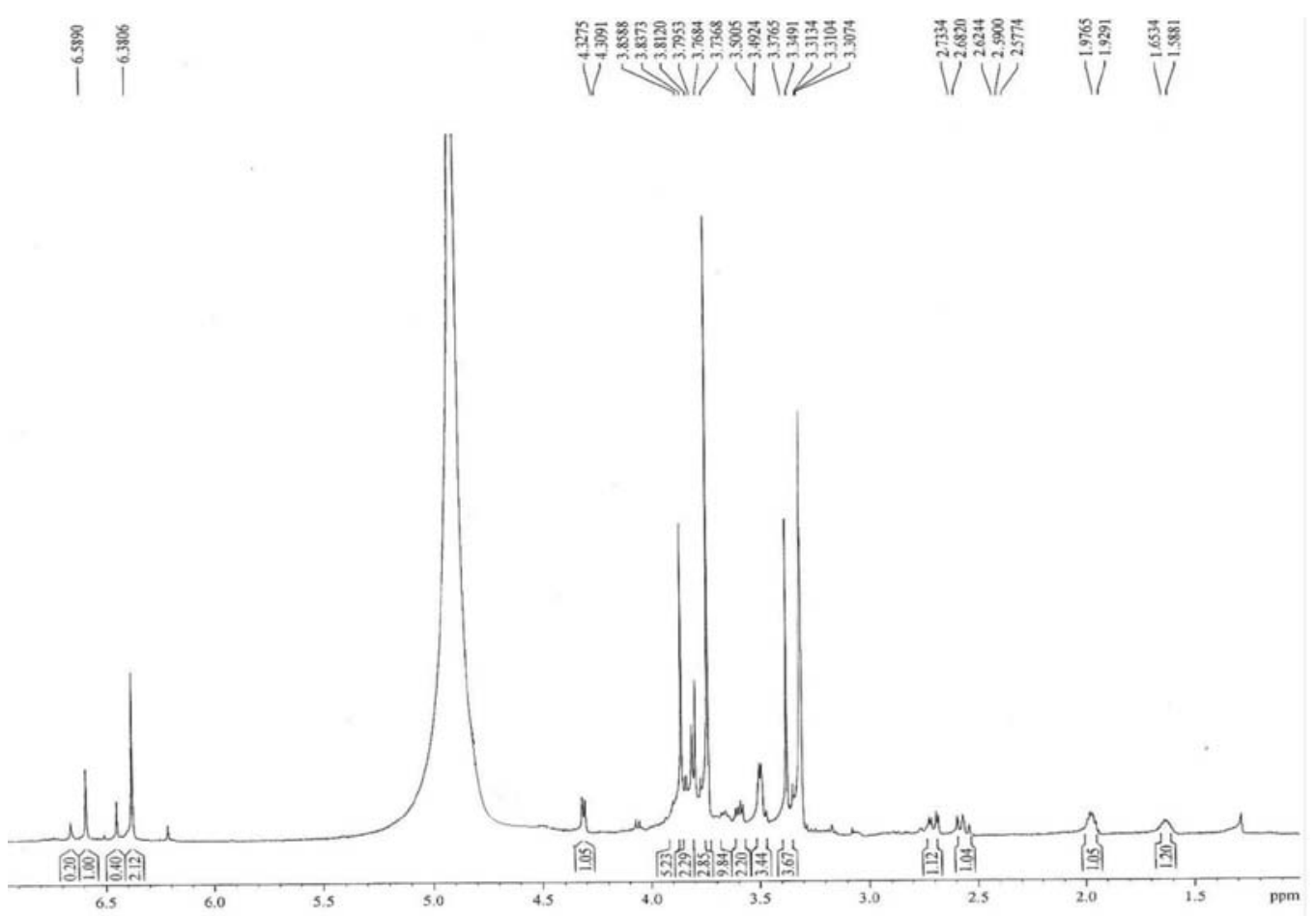

Figura 16S. Espectro de $R M N^{l}{ }^{1}\left(300 \mathrm{MHz}, C D_{3} O D\right)$ de 9

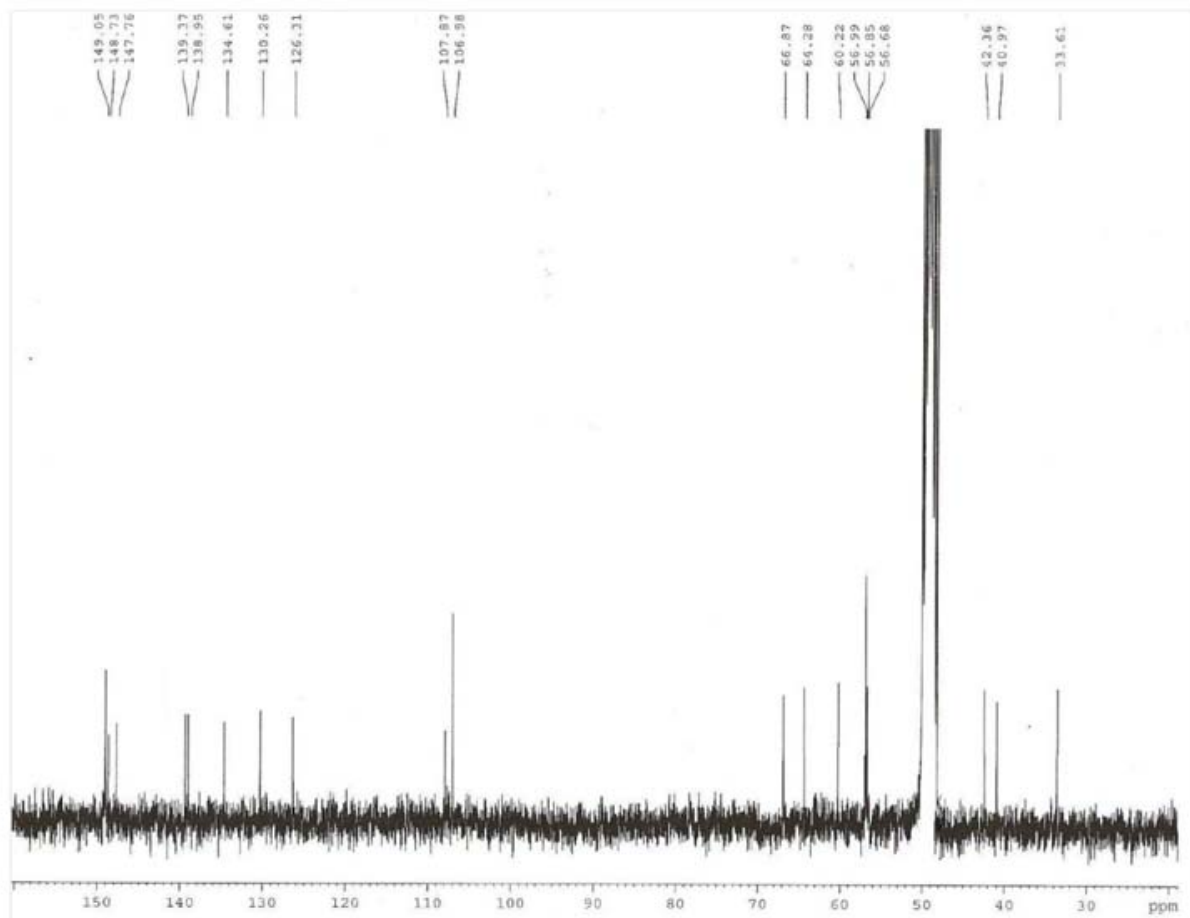

Figura 17S. Espectro de $\mathrm{RMN}^{13} \mathrm{C}\left(75 \mathrm{MHz}, \mathrm{CD}_{3} \mathrm{OD}\right)$ de 9 


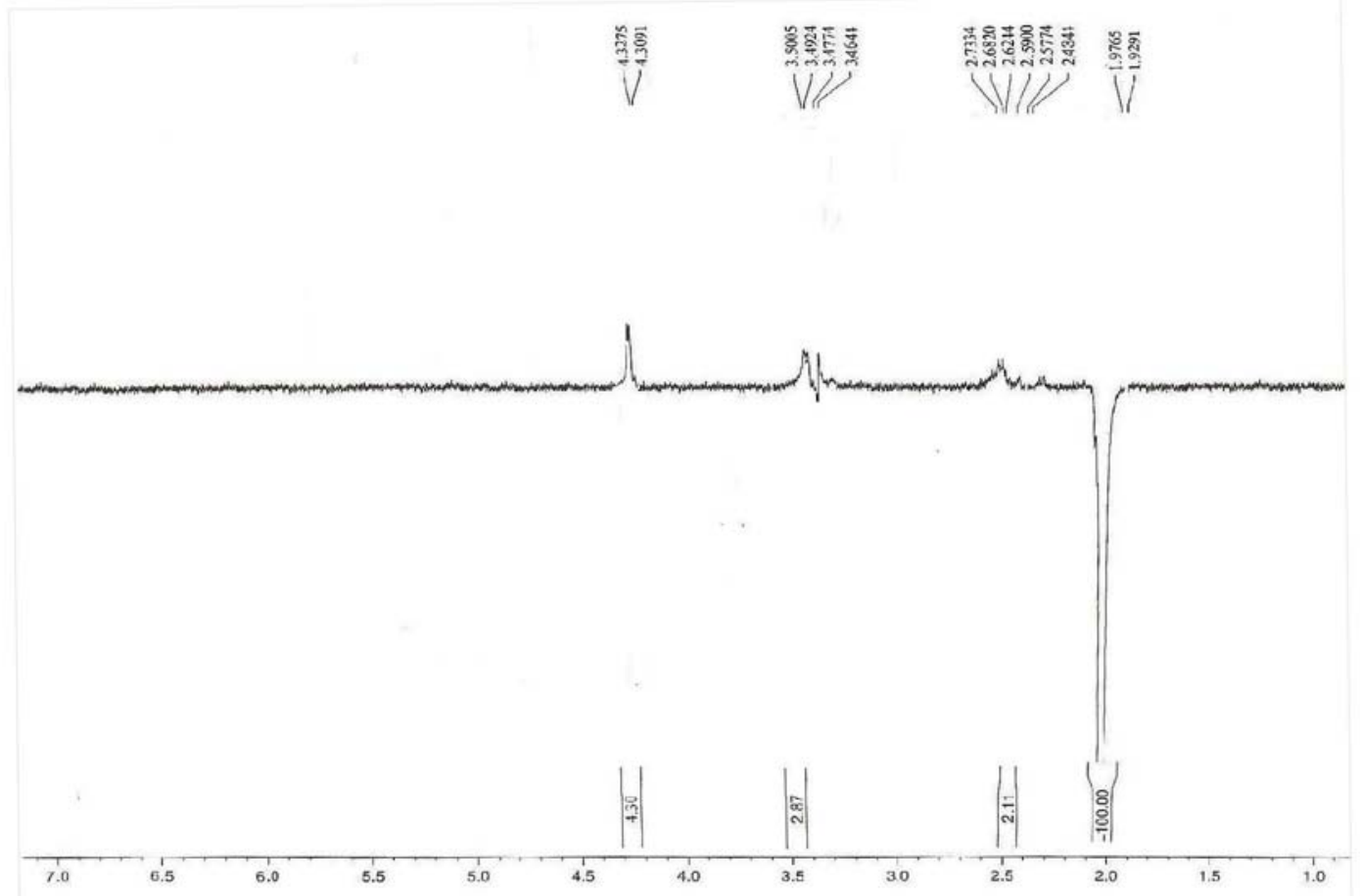

Figura 18S. Espectro de $\mathrm{RMN}^{1} \mathrm{H} N \mathrm{NOE}$ seletivo $\left(300 \mathrm{MHz}, \mathrm{CD}_{3} \mathrm{OD}\right)$ de 9

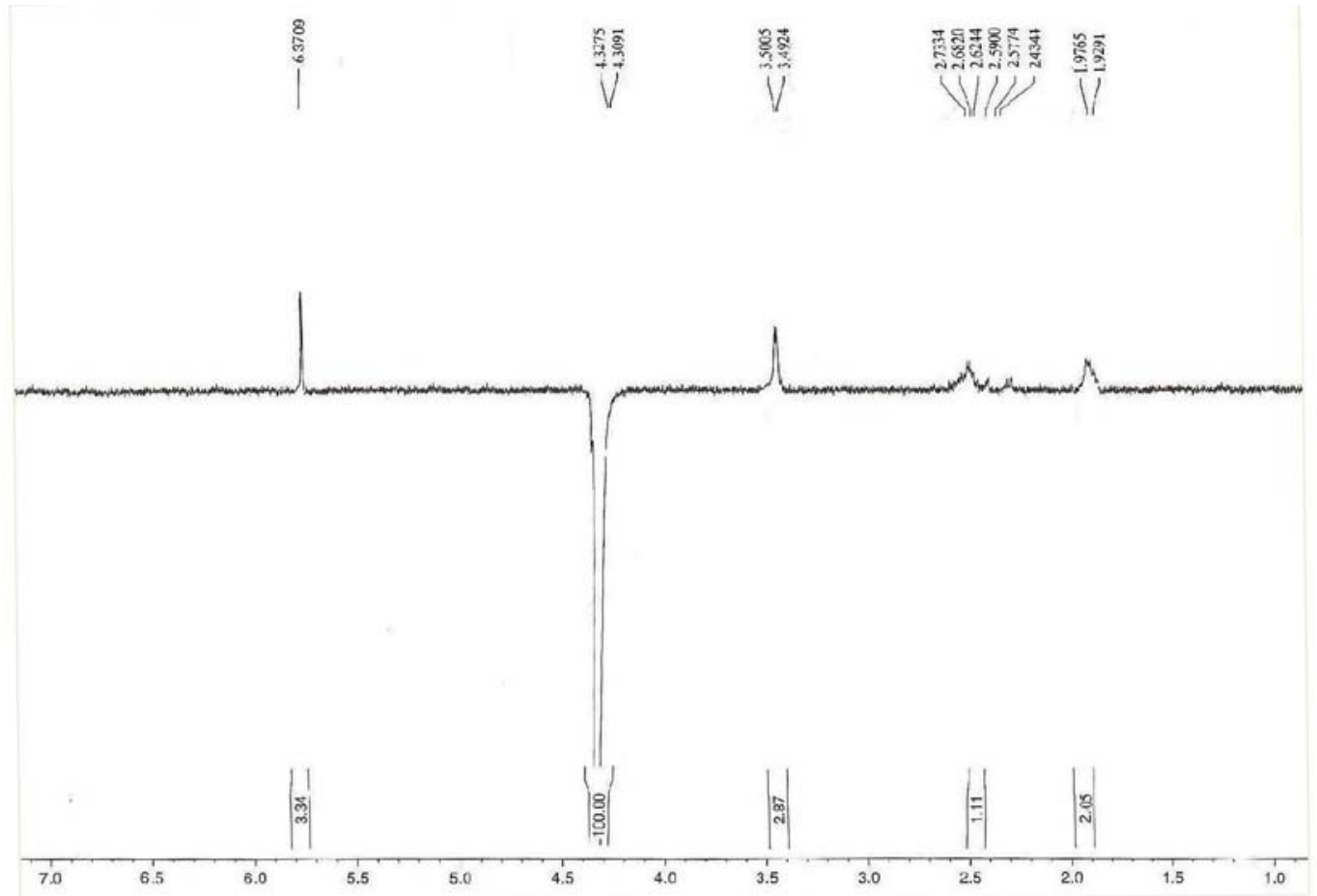

Figura 19S. Espectro de RMN ${ }^{l} \mathrm{H} N O E$ seletivo $\left(300 \mathrm{MHz}, \mathrm{CD}_{3} \mathrm{OD}\right)$ de 9 


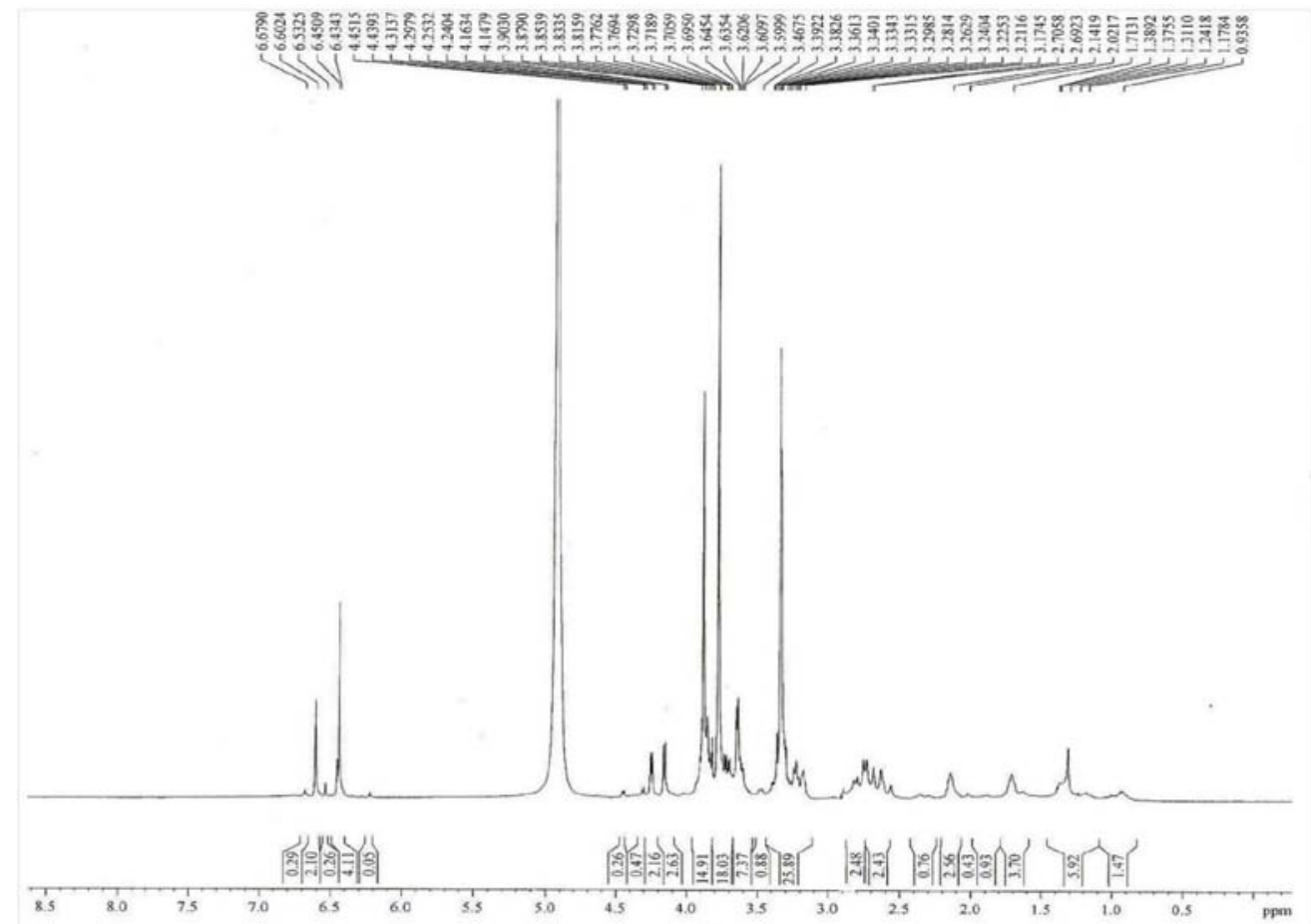

Figura 20S. Espectro de $\mathrm{RMN}^{l} \mathrm{H}\left(300 \mathrm{MHz}, \mathrm{CD}{ }_{3} \mathrm{OD}\right)$ de 10

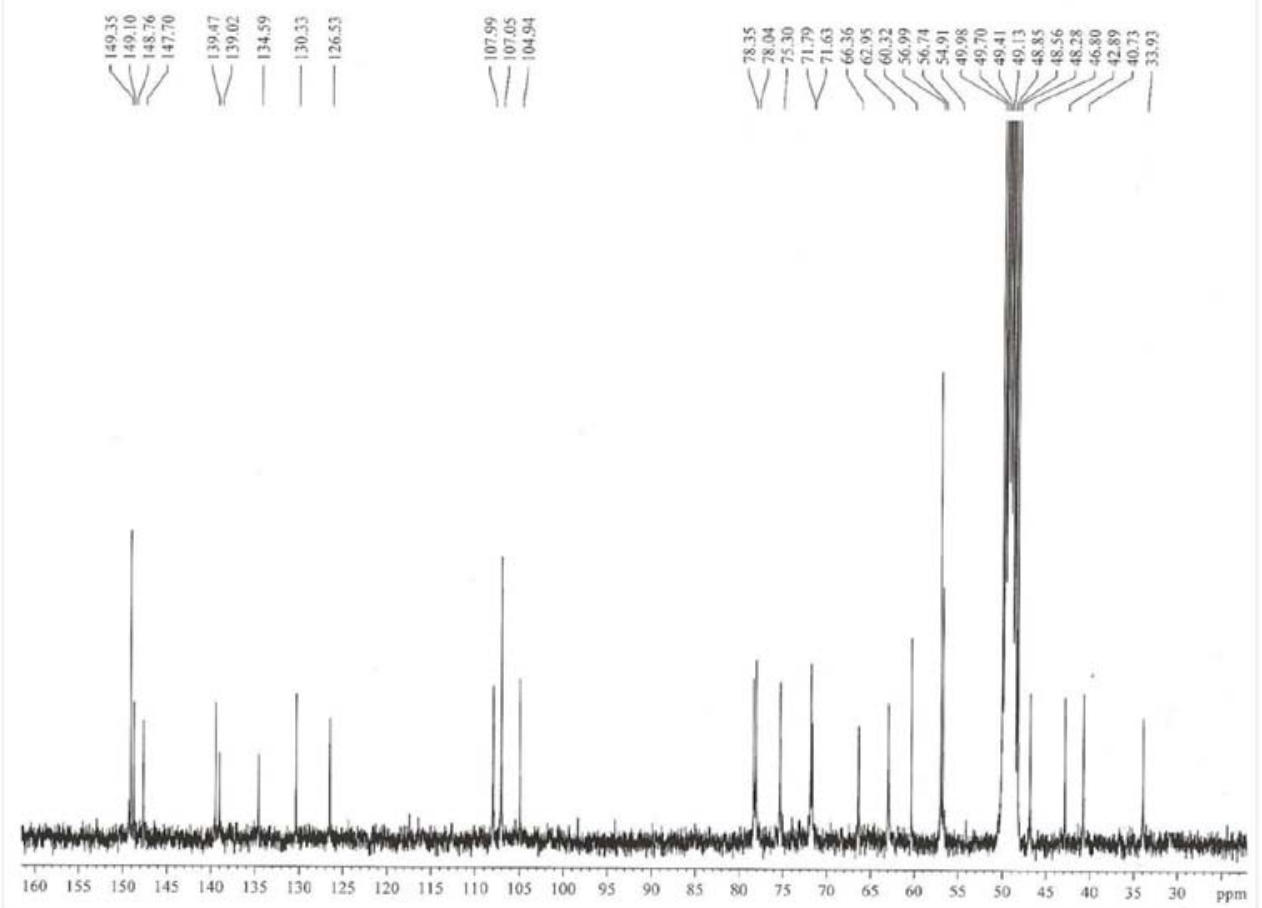

Figura 21S. Espectro de $\mathrm{RMN}^{13} \mathrm{C}\left(75 \mathrm{MHz}, \mathrm{CD}_{3} \mathrm{OD}\right)$ de 10 


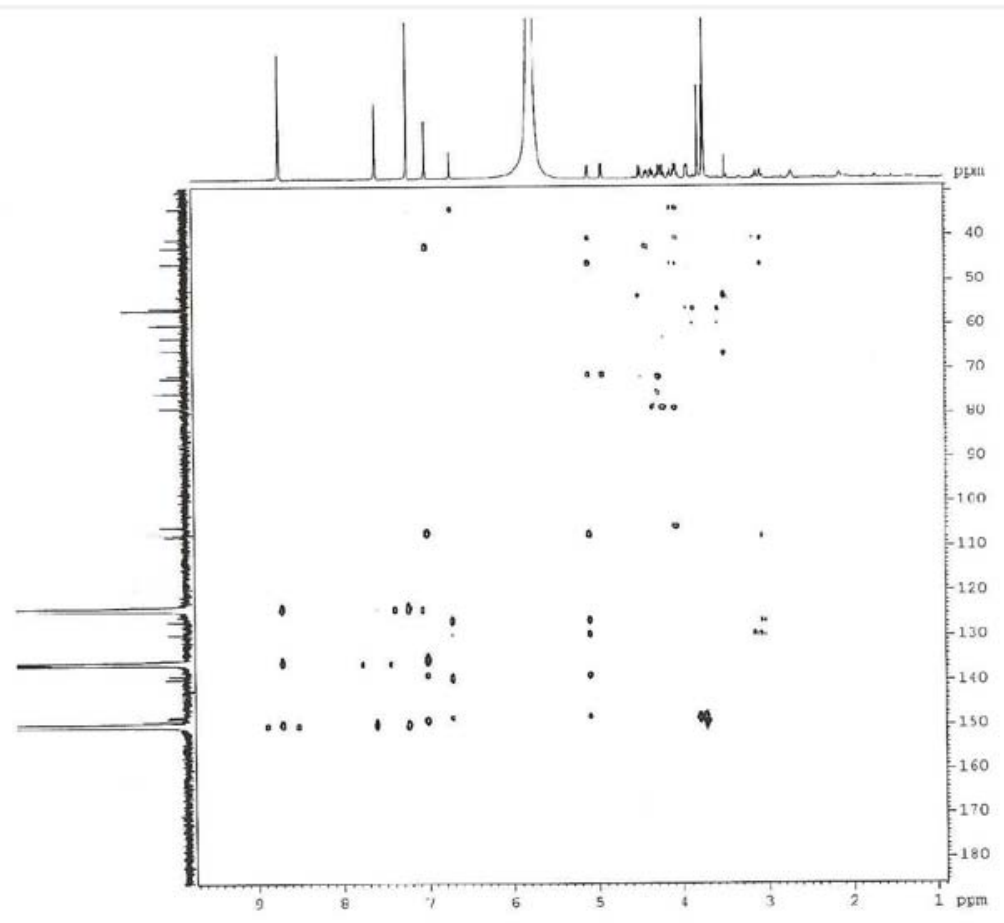

Figura 22S. Espectro de $R M N^{1} H,{ }^{13} \mathrm{C} H M B C\left(500 \times 125 \mathrm{MHz}, \mathrm{C}_{5} \mathrm{D}_{5} \mathrm{~N}\right)$ de $\mathbf{1 0}$

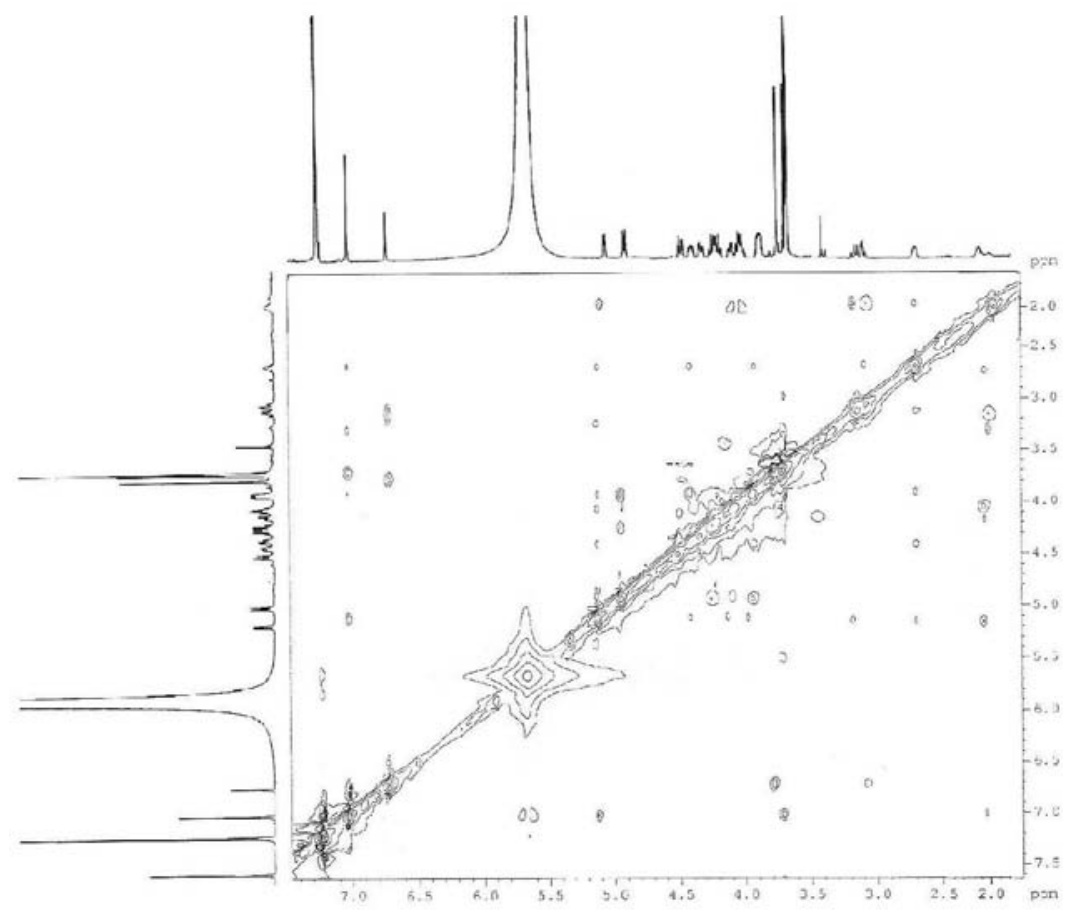

Figura 23S. Espectro de RMN ${ }^{l} \mathrm{H},{ }^{l} \mathrm{H} \operatorname{NOESY}\left(500 \times 500 \mathrm{MHz}, C_{5} D_{5} \mathrm{~N}\right)$ de 10 


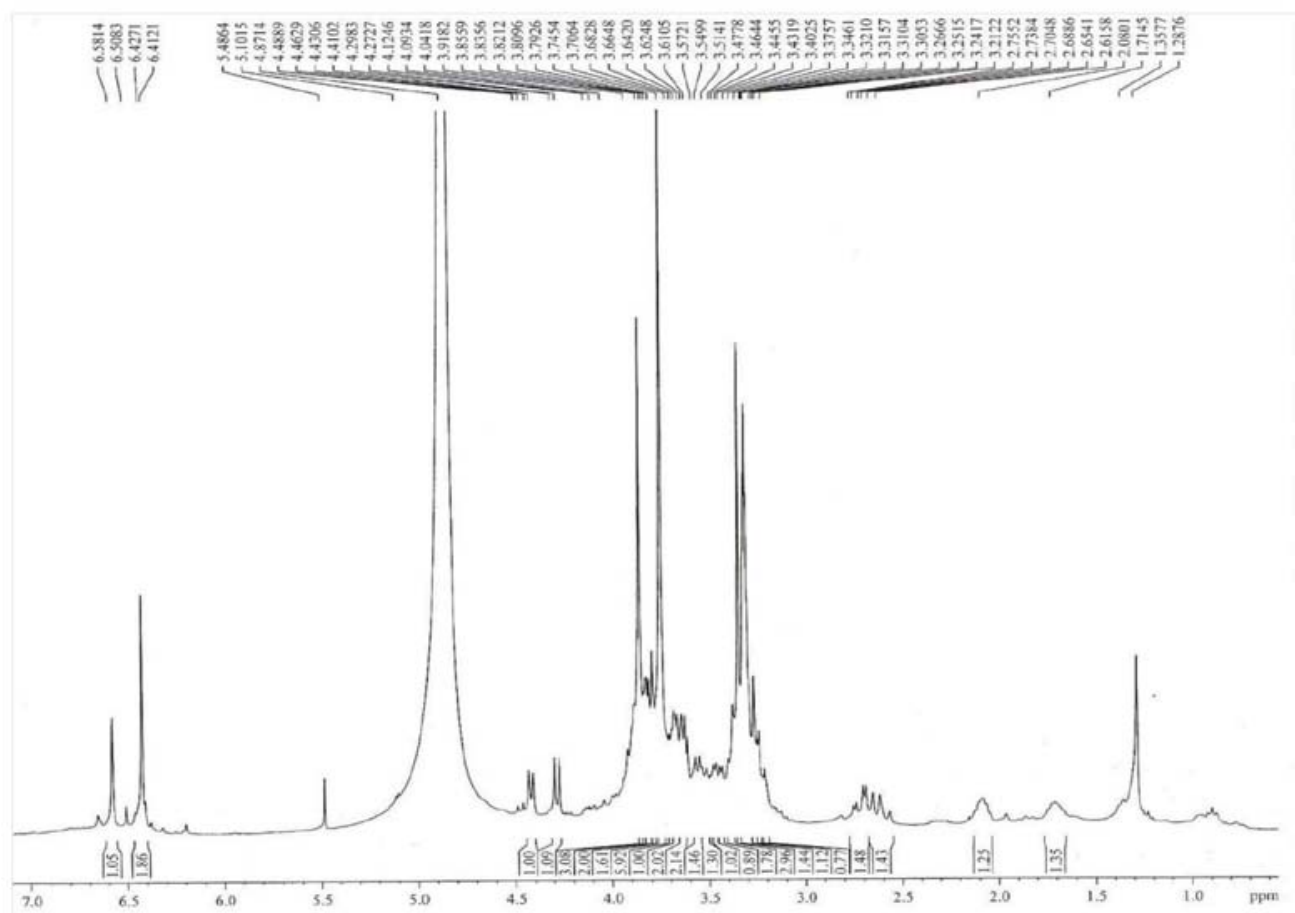

Figura 24S. Espectro de $\mathrm{RMN}^{l} \mathrm{H}\left(300 \mathrm{MHz}, \mathrm{CD}{ }_{3} \mathrm{OD}\right)$ de 11

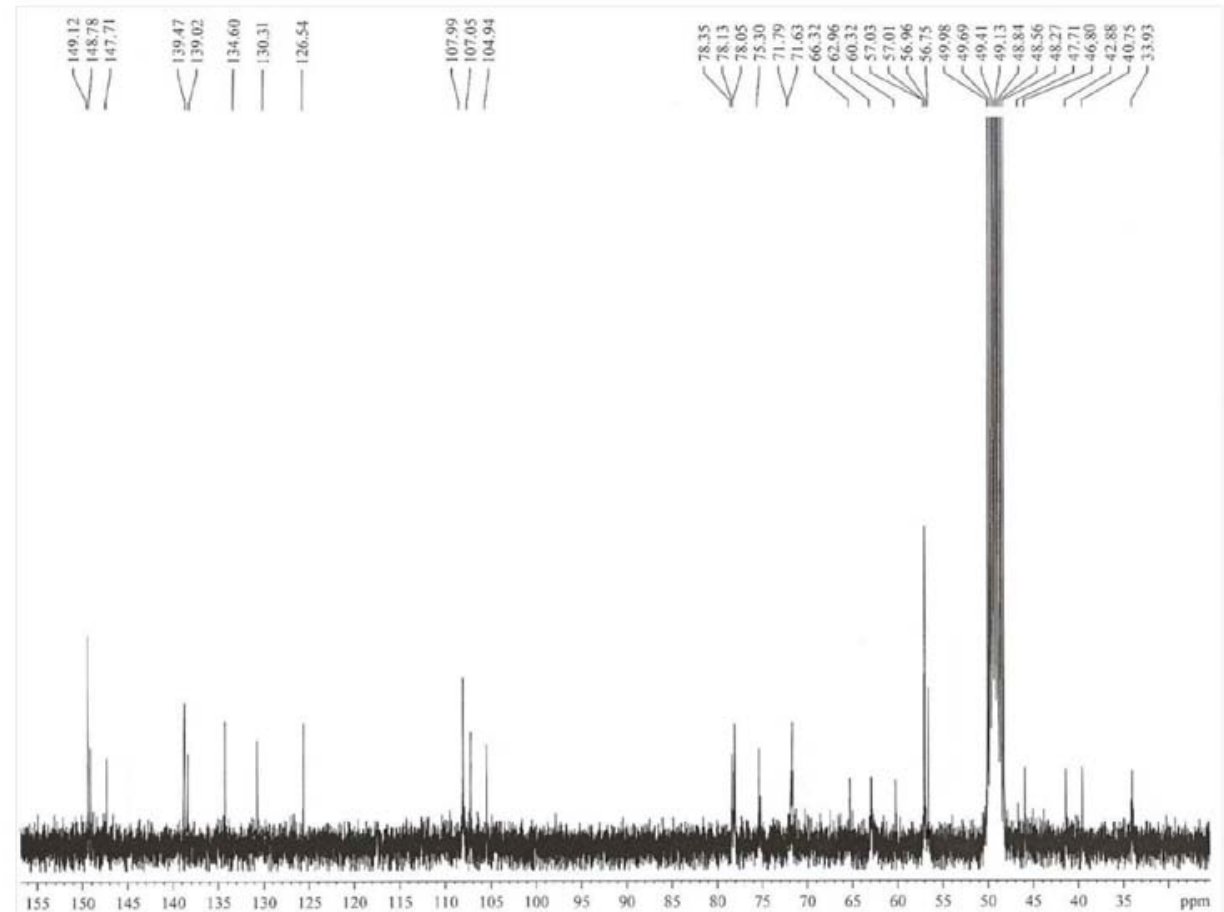

Figura 25S. Espectro de $\mathrm{RMN}^{13} \mathrm{C}\left(75 \mathrm{MHz}, \mathrm{CD}_{3} \mathrm{OD}\right)$ de $\mathbf{1 1}$ 
S14

Pinto et al.

Quim. Nova

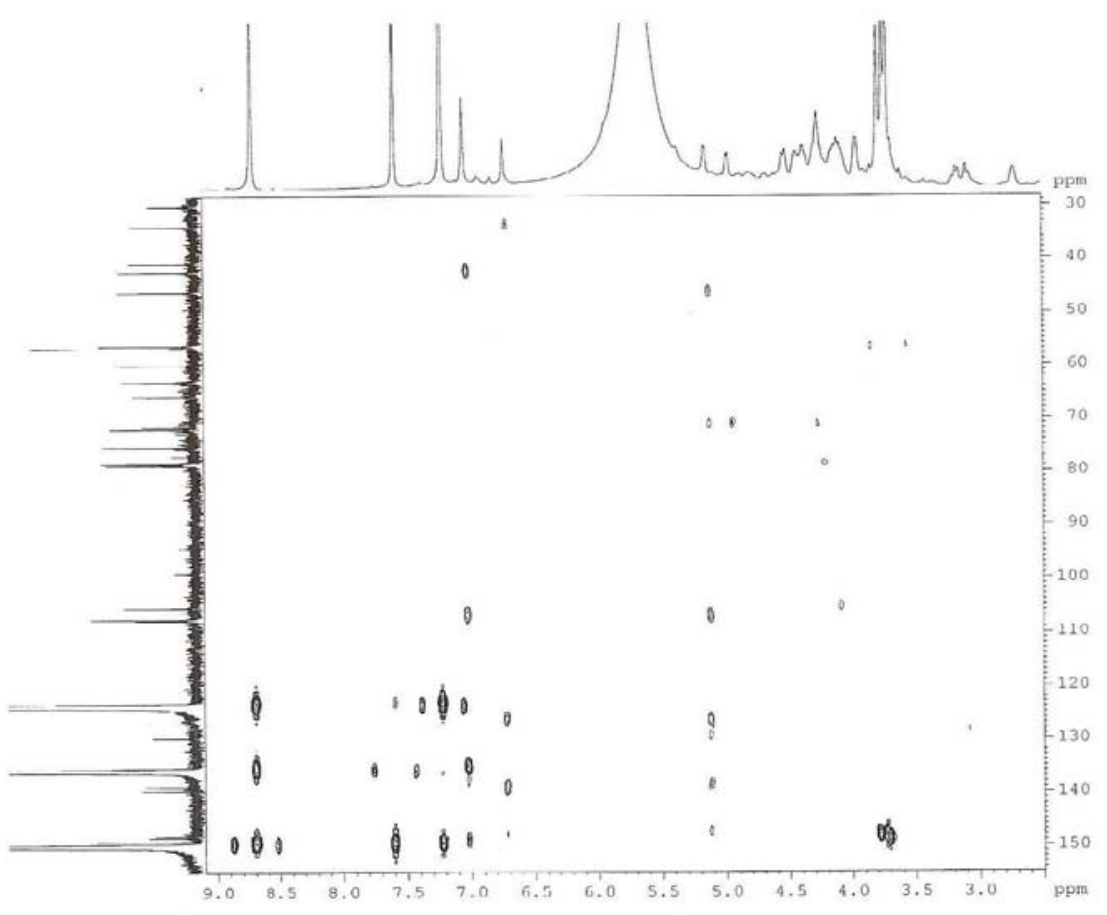

Figura 26S. Espectro de $\mathrm{RMN}^{1} \mathrm{H},{ }^{13} \mathrm{C} H \mathrm{HBC}\left(500 \times 125 \mathrm{MHz}, \mathrm{C}_{5} \mathrm{D}_{5} \mathrm{~N}\right)$ de 11

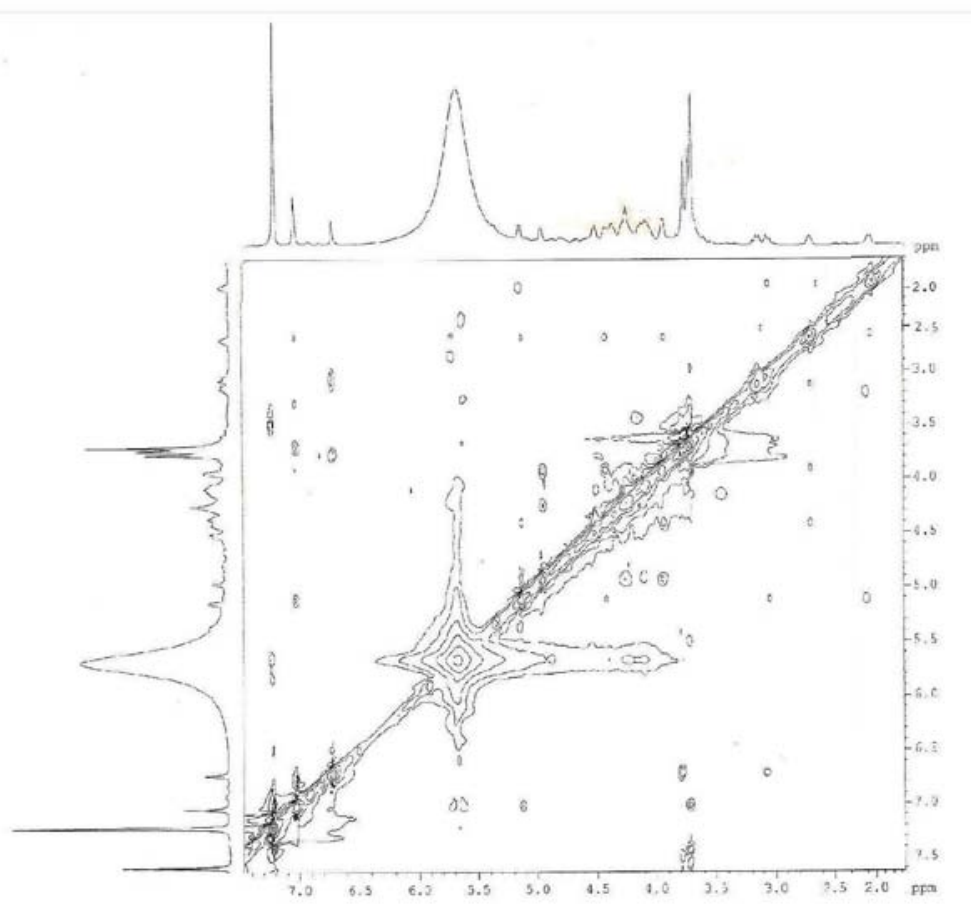

Figura 27S. Espectro de $R M N^{l} H,{ }^{l} H$ NOESY $\left(500 \times 500 \mathrm{MHz}, C_{5} D_{5} N\right)$ de 11 


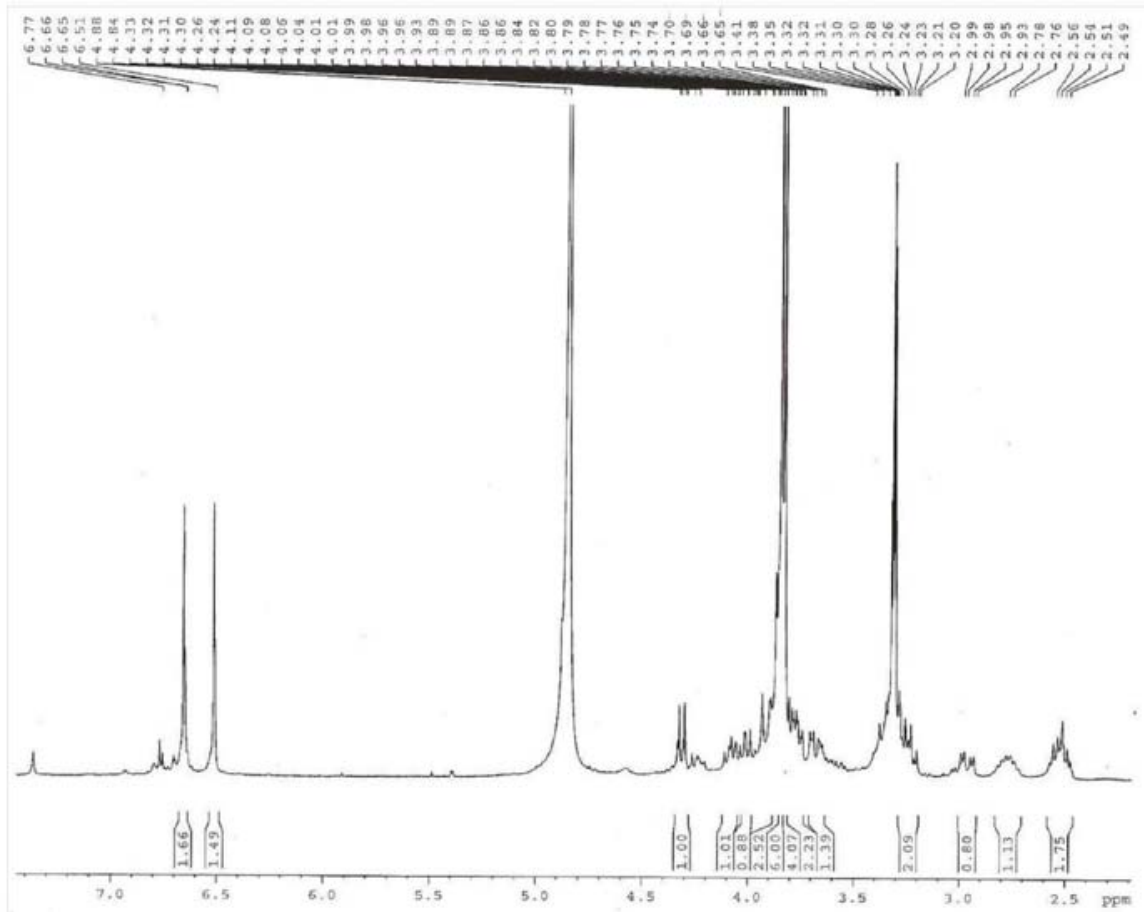

Figura 28S. Espectro de $\mathrm{RMN}^{l} \mathrm{H}\left(300 \mathrm{MHz}, \mathrm{CD}{ }_{3} \mathrm{OD}\right)$ de 12

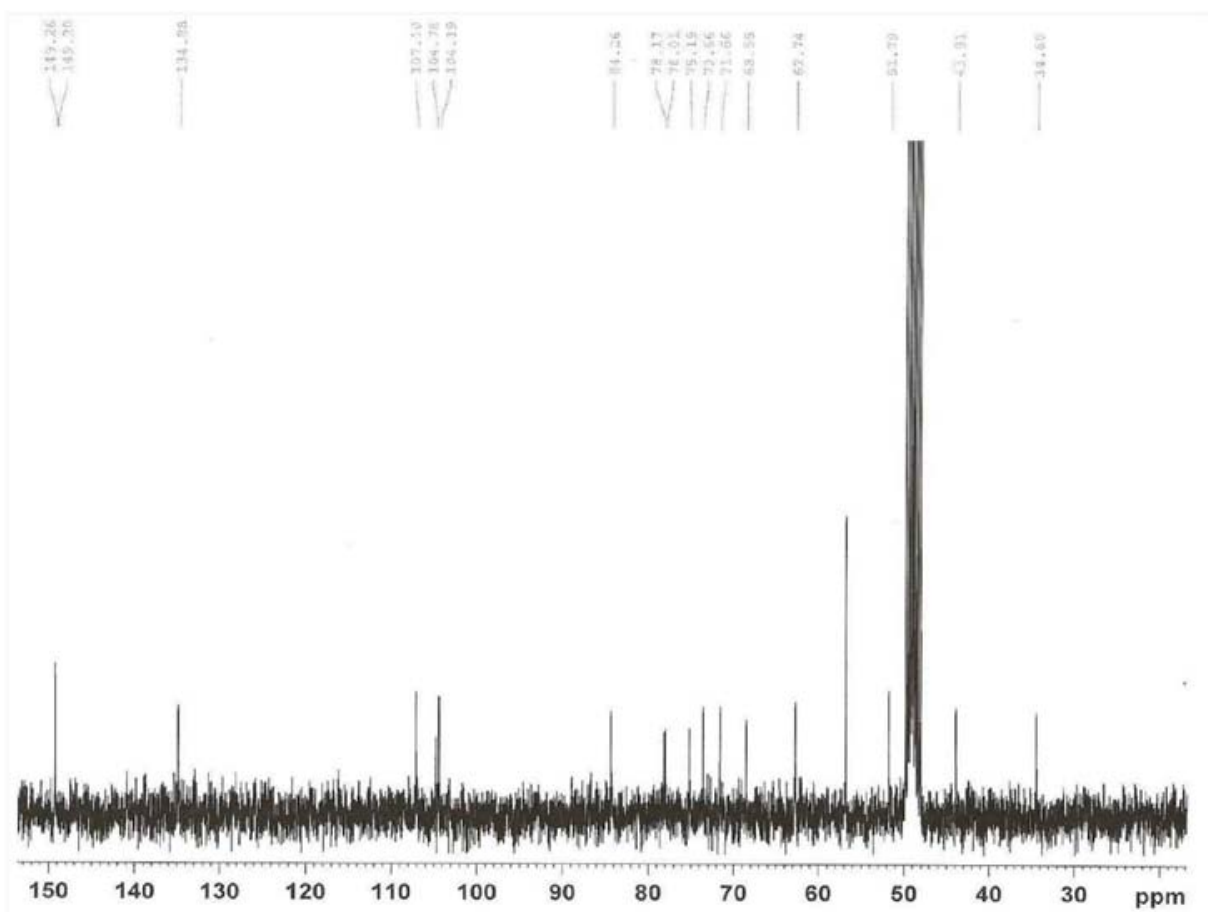

Figura 29S. Espectro de $\mathrm{RMN}^{13} \mathrm{C}\left(75 \mathrm{MHz}, C D_{3} \mathrm{OD}\right)$ de $\mathbf{1 2}$ 


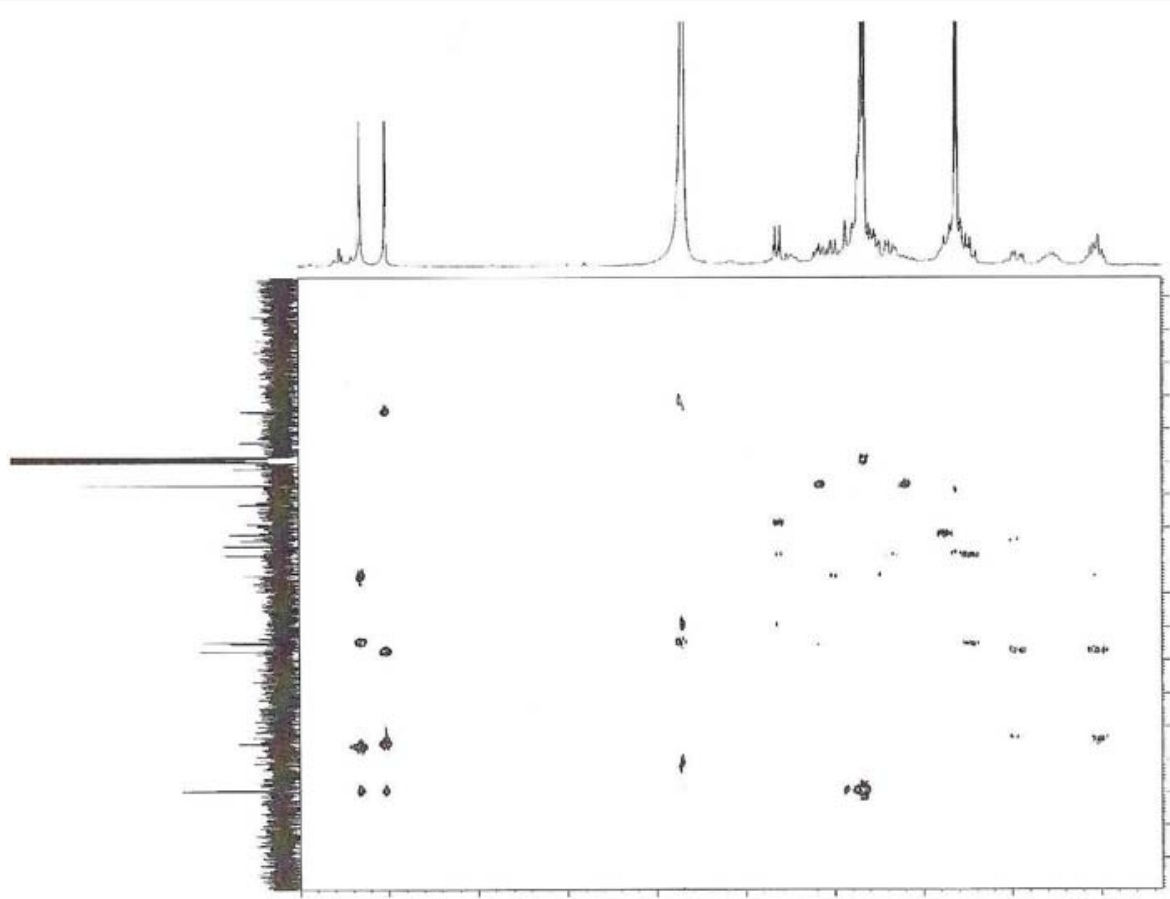

Figura 30S. Espectro de $\mathrm{RMN}^{1} \mathrm{H},{ }^{13} \mathrm{C} \mathrm{HMBC}\left(300 \times 75 \mathrm{MHz}, \mathrm{CD}_{3} \mathrm{OD}\right)$ de 12

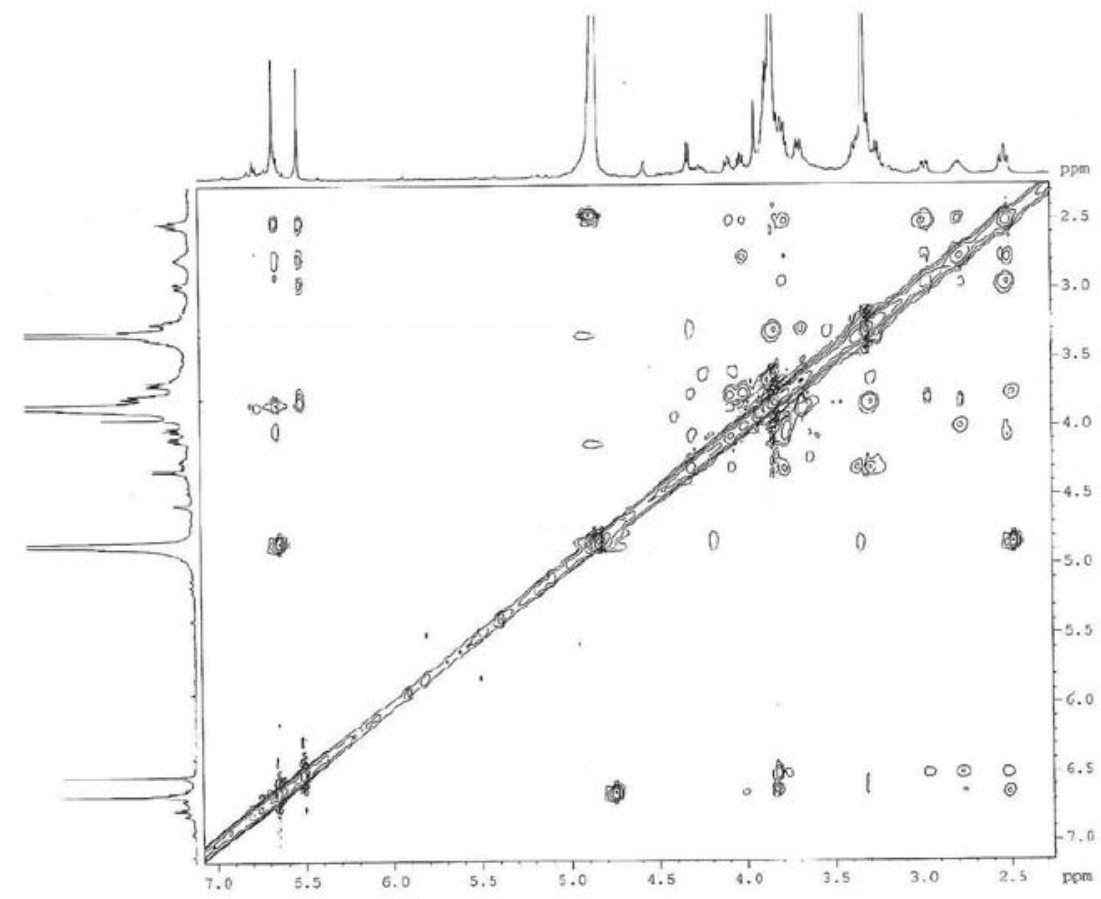

Figura 31S. Espectro de $R M N^{l} \mathrm{H},{ }^{l} \mathrm{H} N O E S Y\left(300 \times 300 \mathrm{MHz}, C D_{3} O D\right)$ de 12 

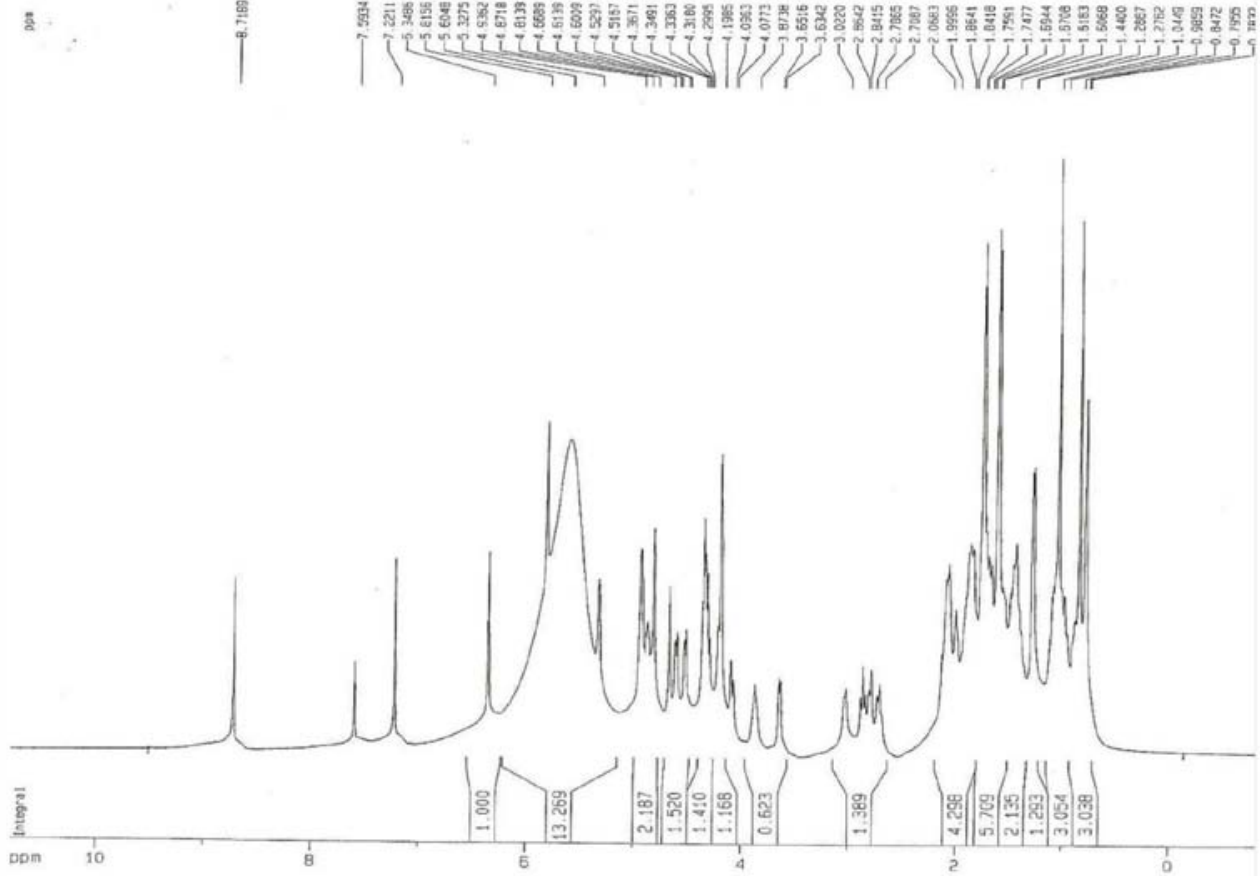

Figura 32S. Espectro de $R M N^{1} \mathrm{H}\left(500 \mathrm{MHz}, \mathrm{C}_{5} \mathrm{D}_{5} \mathrm{~N}\right)$ de 13

ริ

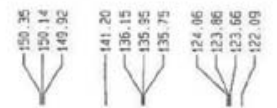

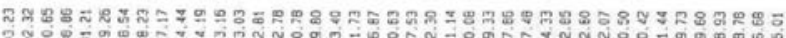

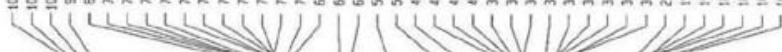

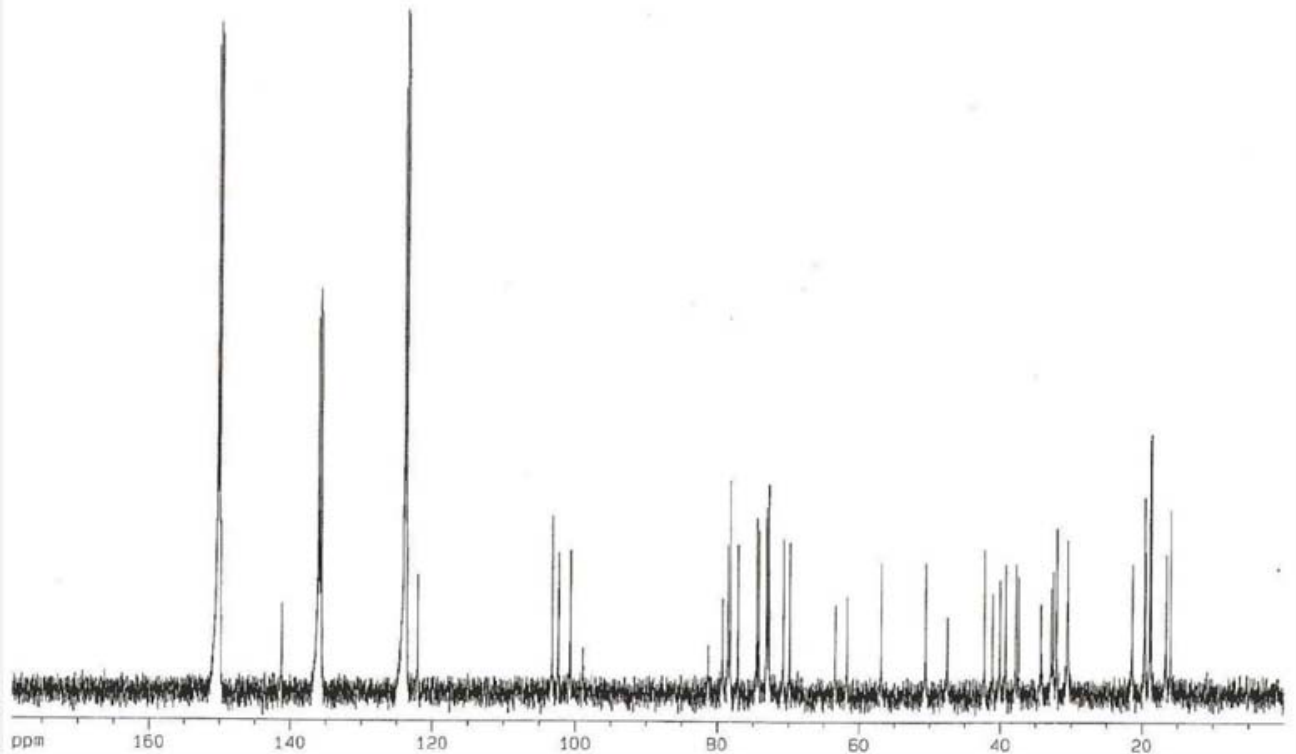

40

Figura 33S. Espectro de $R M N{ }^{13} \mathrm{C}\left(125 \mathrm{MHz}, \mathrm{C}_{5} \mathrm{D}_{5} \mathrm{~N}\right)$ de 13 